\title{
OPEN Wheat (Triticum aestivum) adaptability evaluation in a semi-arid region of Central Morocco using APSIM model
}

\begin{abstract}
Hamza Briak ${ }^{\circledR}$ \& Fassil Kebede
In this study, we evaluated the suitability of semi-arid region of Central Morocco for wheat production using Agricultural Production Systems sIMulator (APSIM) considering weather, soil properties and crop management production factors. Model calibration was carried out using data collected from field trials. A quantitative statistics, i.e., root mean square error (RMSE), Nash-Sutcliffe efficiency (NSE), and index of agreement (d) were used in model performance evaluation. Furthermore, series of simulations were performed to simulate the future scenarios of wheat productivity based on climate projection; the optimum sowing date under water deficit condition and selection of appropriate wheat varieties. The study showed that the performance of the model was fairly accurate as judged by having $\mathrm{RMSE}=0.13$, NSE $=0.95$, and $d=0.98$. The realization of future climate data projection and their integration into the APSIM model allowed us to obtain future scenarios of wheat yield that vary between 0 and $2.33 \mathrm{t} / \mathrm{ha}$ throughout the study period. The simulated result confirmed that the yield obtained from plots seeded between 25 October and 25 November was higher than that of sown until 05 January. From the several varieties tested, Hartog, Sunstate, Wollaroi, Batten and Sapphire were yielded comparatively higher than the locale variety Marzak. In conclusion, APSIM-Wheat model could be used as a promising tool to identify the best management practices such as determining the sowing date and selection of crop variety based on the length of the crop cycle for adapting and mitigating climate change.
\end{abstract}

Wheat (Triticum aestivum) is one of the most important cereal crops and vital staple food worldwide ${ }^{1,2}$, for the reasons that it grows in both the temperate and warmer regions due to its resilience to drought and frosts. Moreover, wheat grain is nutritious and composed of starch, fiber, vitamins B and E, iron and antioxidants. Besides, it has a gluten content which is capable of forming the fully elastic dough required for baking leavened bread, and is also an essential ingredient globally in the food industry sector for making great varieties of food stuff $^{3-5}$. Wheat yield in the 2019 cropping season were $3.55 \mathrm{t} /$ ha in the world, $2.76 \mathrm{t} / \mathrm{ha}$ in Africa, $2.74 \mathrm{t} / \mathrm{ha}$ in North Africa and $1.61 \mathrm{t} / \mathrm{ha}$ in Morocco ${ }^{6}$. Compared to the year of 2018, wheat yield in the world increased by $3 \%$ in contrast to Morocco where the yield declined by $37 \%$. As a result, Morocco has become among the top 10 wheat importing countries ${ }^{7}$. The decline of Morocco's wheat production in recent years has been attributed due to low and erratic precipitation with a frequent drought ${ }^{8}$, and unusually high mean temperature. In fact, since the world population is projected to be around 9.8 billion by 2050 , wheat yield is expected to be increased by $60 \%{ }^{9}$. The key to tackle these challenges is to adapt best management practices, which are helpful for optimizing wheat grain yield such as setting an optimum sowing date and using an appropriate wheat variety for the region ${ }^{5,10-20}$. Many studies confirm that the early and medium sowing date was beneficial for improving the soil water storage and increased the grain yield, and a reduction in yield and development of wheat when sowing is delayed after the optimum time, especially in a dry year ${ }^{21-26}$. But just a few studies which confirm that late sowing increases wheat yield ${ }^{27}$. Furthermore, the choice of the suitable cultivars for the specific environment is also one of the best management practices to increase the yield ${ }^{5,12,15,20,28-30}$.

Application of crop simulation models helps in elaborating the suitability of best management practices to boost agricultural productivity by integrating the interdisciplinary knowledge gained through experimentation and technological innovations in the fields of biological, physical, and chemical science relating to the agricultural production system ${ }^{31-34}$. They are widely used for decision making and planning in agriculture and can be 


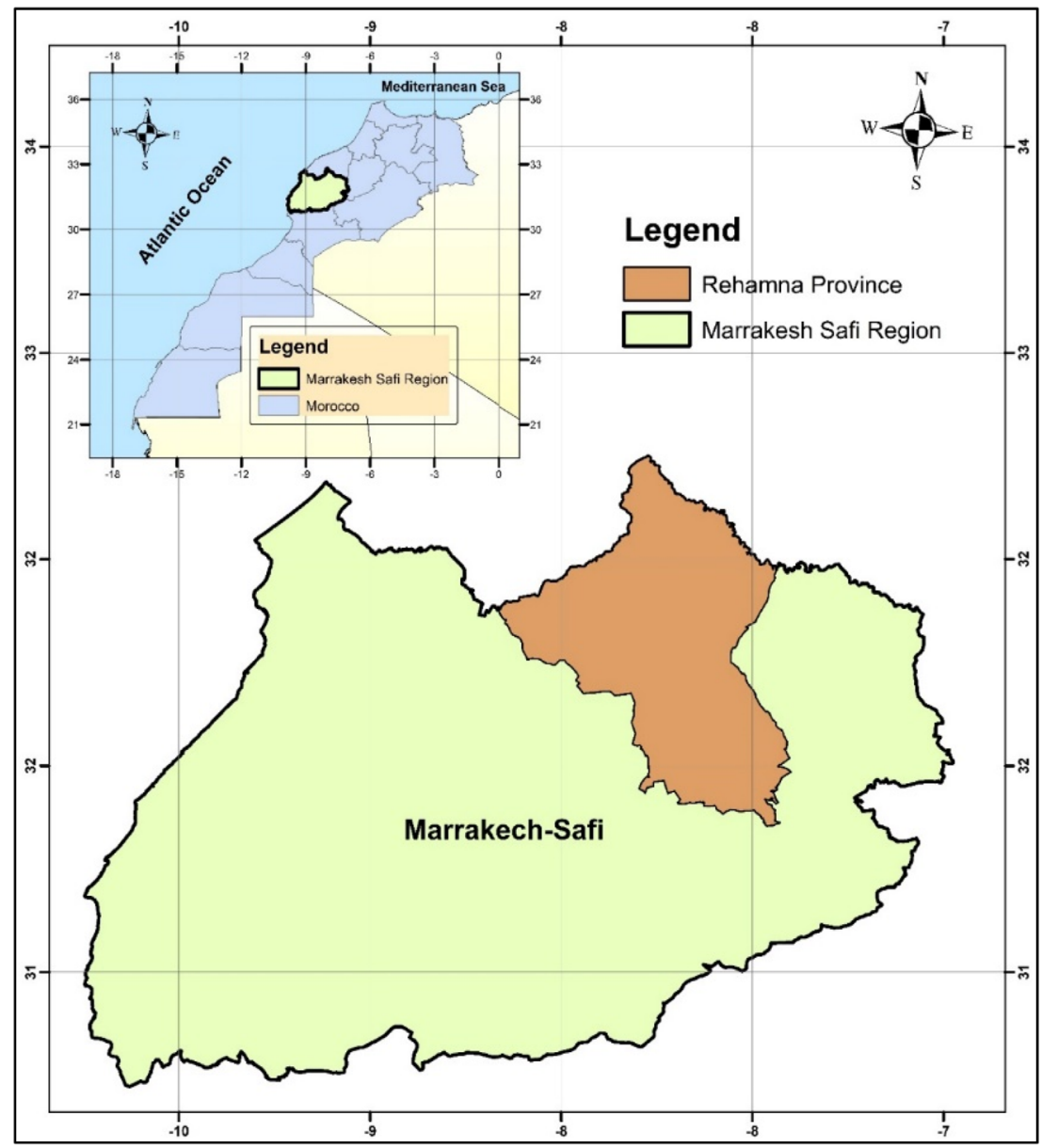

Figure 1. Geographical location of Rhamna region.

particularly useful for predicting food production in response to climate change ${ }^{35-37}$. The Agricultural Production Systems Simulator (APSIM) ${ }^{38}$ is one of the most appropriate models for agricultural systems. The model has been used successfully for simulating crop adaptation, efficient and sustainable production. It is particularly designed and suited for assessing the impacts of alternative management practices on the soil properties and crop productivity through the linking of crop growth with soil processes in different climates ${ }^{39,40}$. APSIM is also concerned about the long-term repercussions of the actions of farmers, for example, on yield levels and soil nutrient status. Keating et al. ${ }^{38}$ noted that the main thrust of APSIM is a combination of crop yield estimation, as a result of how farmers manage their farming systems, and the effects of these management decisions in the long run. To establish the applicability of the APSIM model, it is necessary to evaluate it in order to assess its capability to predict experienced outcomes in the real world. APSIM model has been used to simulate the performance crop production under stress conditions over the world and in various environments such as arid, semi-arid and Mediterranean climates ${ }^{41-46}$. APSIM's performance was statistically assessed against field trial data. After properly parameterizing, the model performs well in simulating the yield limiting factors. Nevertheless, APSIM model has not been tested yet in the Moroccan context, thus far. Therefore, this work was carried out to evaluate the APSIM's applicability to simulate wheat production factors in Central Morocco.

The overall goal of this study was to evaluate wheat production in Central Morocco as a function of weather, soil properties and crop management using APSIM model.

\section{Materials and methods}

Study of the site description. The study was conducted in the Marrakech Safi region, which is located in Central Morocco (Fig. 1), covering an area of $41,404 \mathrm{~km}^{2}$, which represents $6 \%$ of the national territory. This region consists of seven provinces (i.e., Safi, Al Haouz, El Kelâa des Sraghna, Rhamna, Youssoufia, Chichaoua and Essaouira), where $23.6 \%$ of the national farmlands are located (i.e., 5,821,800 hectares) ${ }^{47}$. Fundamentally, this study focuses on the Rhamna province as it is a number one cereal and legume growing belt, which accounts for $16.81 \%$ of the farmland of Morocco. In fact, it stands sixth position in term of the total regional cereal production $(8.74 \%)$ and fifth in terms of the total regional legume production $(4.74 \%)^{48}$. Rhamna covers $5877 \mathrm{~km}^{2}$ with a population of 315,077 inhabitants, and it is a semi-arid region with fertile soil and limited water resources. However, the agricultural sector, which is one of the pillars of the regional economy, faces several problems, 


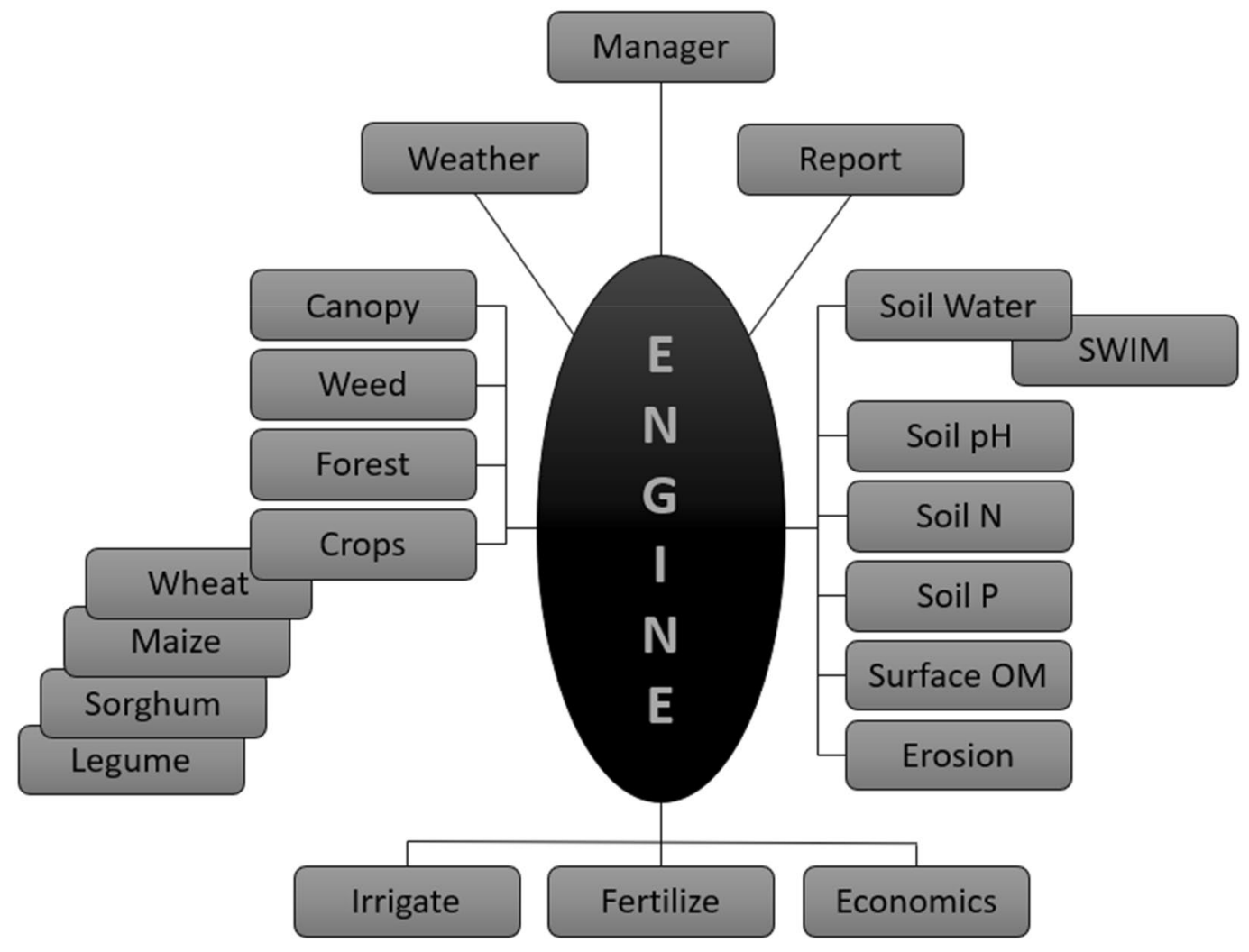

Figure 2. Modules and engine of APSIM ${ }^{38,53,69,70}$.

namely: the aridity of the climate, the poor structuring of irrigation water and the salinization of agricultural land, which limits the development of modern agriculture to high yield.

The map (Fig. 1) was edited using ArcGIS software (10.6 version), based on input vector layers of Moroccan administrative units (ESRI shapefile format). The input data was downloaded from (www.geodatashp.com).

APSIM model structure and research design. The Agricultural Production Systems sIMulator (APSIM) is a dynamic farming systems simulation model that combines biophysical and management modules within a central engine (Fig. 2) on a daily time-step ${ }^{38,49-51}$. According to Climate Kelpie ${ }^{52}$, APSIM simulates effects of environmental variables and farm management decisions on crop yield and profits. The fact that APSIM is made out of different soil modules, a range of crop modules and crop management options under different climates makes it an accurate tool for predicting crop yields, if all the data input is done correctly. This also implies that it can be used everywhere in the world, including in small-scale farming systems of Africa, as long as it is validated for local conditions and crops. The development of the APSIM model was firstly focused on the estimation of crop yield as influenced by the availability of water and nitrogen ${ }^{53}$, but it expanded to include other agricultural systems and environmental processes ${ }^{54-56}$. The suite of modules that contains the APSIM software framework enable the simulation of farming systems for a diverse range of plant ${ }^{57}$, crop types ${ }^{58}$, cropping systems rotation $s^{59}$, management ${ }^{60}$, soil water ${ }^{61}$, soil organic carbon ${ }^{62}$, soil nutrients ${ }^{63}$, animals ${ }^{64}$, trees $^{65}$, climate clim $^{42,66}$ and Genotype ${ }^{\star}$ Environment ${ }^{*}$ Management interactions ${ }^{67}$. The simulator is recognized worldwide as a highly advanced platform for modelling and simulation of agricultural systems ${ }^{68}$. In this study, the APSIM model v7.10 (www.apsim.info) was used for predicting the wheat yield at different sowing dates, as well as assessing the reliability of the simulations against the measured yield data.

Data input for APSIM. Observed climate data. The daily measured climatic data (rainfall and temperature) were collected from the meteorological station ( $\left.32^{\circ} 15^{\prime} 10.2^{\prime \prime} \mathrm{N} ; 7^{\circ} 57^{\prime} 11.9^{\prime \prime} \mathrm{W}\right)$ of National Office of Agricultural Council (ONCA) in Ben Guerir, while the daily radiation was estimated from solar radiation data website (www.soda-pro.com). The climate of the Rhamna region is distinguished by apparent variability.

During the period of this study from 2013 to 2019 (i.e., 7 years), the mean annual rainfall of the province is $168 \mathrm{~mm}$; which is low in quantity and erratic in distribution as well. The lowest precipitation is obtained in July $(0.2 \mathrm{~mm})$, whereas the highest is in the month of November, which is $42.24 \mathrm{~mm}$ (Fig. 3).

Besides, the annual average daily maximum and minimum temperature are $27.03^{\circ} \mathrm{C}$ and $19.12{ }^{\circ} \mathrm{C}$, respectively. August is the hottest month of the year with a maximum and minimum average daily temperature of $37.02{ }^{\circ} \mathrm{C}$ and $27.72{ }^{\circ} \mathrm{C}$, respectively. January is therefore the coldest month of the year with a maximum and minimum average daily temperature in the range respectively of $18.14^{\circ} \mathrm{C}$ and $11.37^{\circ} \mathrm{C}$ (Fig. 4). 


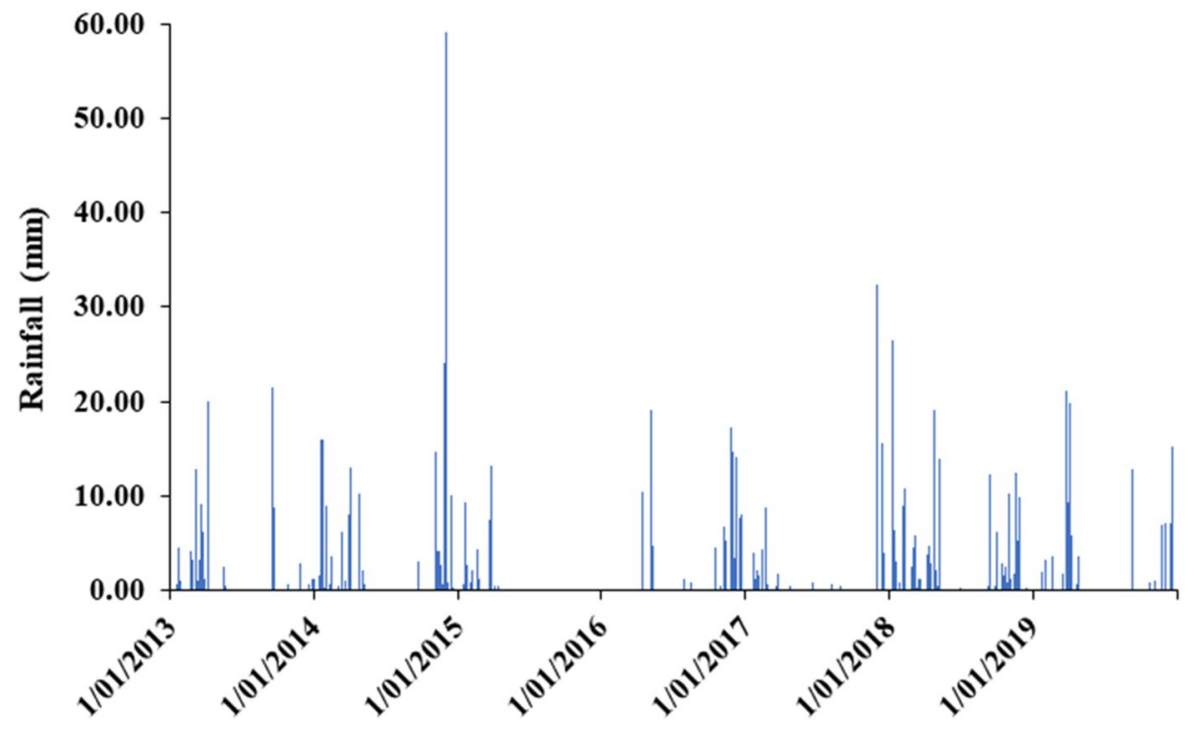

Figure 3. The evolution of rainfall over 7 years' time horizon (2013-2019).

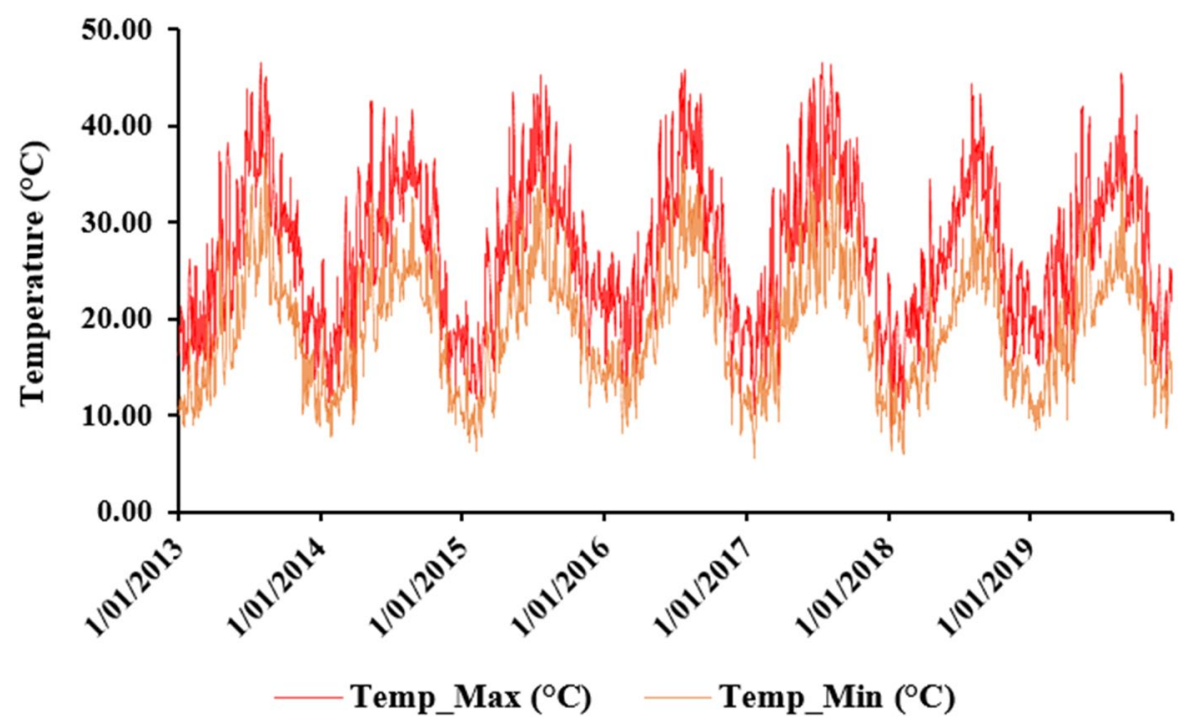

Figure 4. The evolution of maximum and minimum temperature over 7 years' time horizon (2013-2019).

With regard to radiation, Fig. 5 shows the daily solar radiation for 7 years. The annual average daily solar radiation during this period is $19.71 \mathrm{MJ} / \mathrm{m}^{2}$. The highest monthly averaged radiation was detected in June with a value of $28.15 \mathrm{MJ} / \mathrm{m}^{2}$, and the lowest radiation was in December with a value of $11.21 \mathrm{MJ} / \mathrm{m}^{2}$.

Future climate data. To study natural phenomena, such as those occurring in our environment (e.g., climate change), repeated observations of everyone in a population, ordered in time and space, are generally used. Two factors of variability appear on repeated data sets: the variability between observations measured on the same individual and the variability between the individuals themselves. The mixed model is a statistical approach that allows the highlight a relationship between the observed response and the explanatory covariates, taking into account these two types of variation ${ }^{71-74}$. The general mixed models that will be used in this study, are presented in (Eq. 1) according to Laird and Ware ${ }^{75}$ and Littell et al. ${ }^{76}$.

$$
\mathbf{y}_{\mathbf{i}}=\mathrm{X}_{\mathbf{i}} \boldsymbol{\beta}+\mathbf{Z}_{\mathbf{i}} \mathbf{U}_{\mathbf{i}}+\varepsilon_{\mathbf{i}},
$$

where for each individual $i, E\left(y_{i} \mid U_{i}\right)=X_{i} \beta+Z_{i} U_{i}$ is the conditional mean of $y_{i}$ given $U_{i}, Z_{i}$ is a matrix $n_{i} \times q$ of incidence of random effects $U_{i}$, we assume that $U_{i} \sim N(0, D)$, where 0 is the vector of dimension $q \times 1, D$ is the covariance matrix of $\mathrm{u}$. We suppose that $\mathrm{u}$ and $\varepsilon$ are independent. We still have the variance of y conditionally to $\mathrm{u}$ is $\operatorname{Var}\left(\mathrm{y}_{\mathrm{i}} \mid \mathrm{U}_{\mathrm{i}}\right)=\operatorname{Var}\left(\varepsilon_{\mathrm{i}}\right)=\mathrm{R}_{\mathrm{i}}$. 


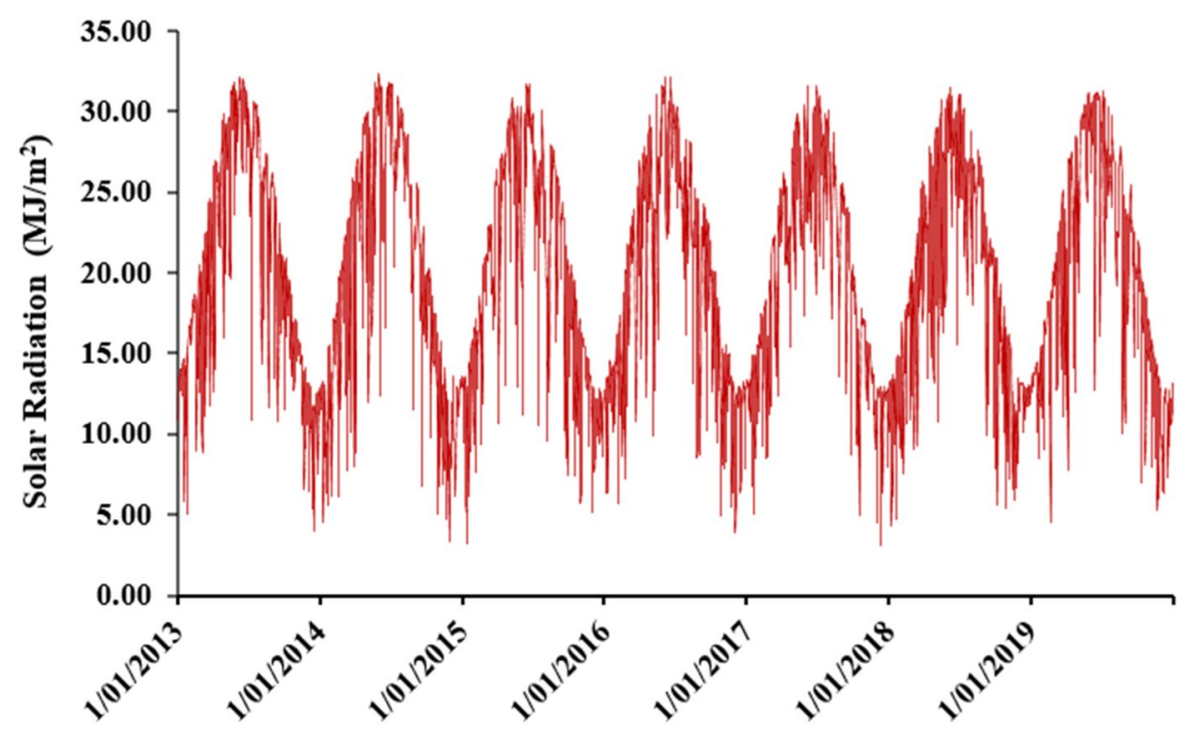

Figure 5. The evolution of solar radiation over 7 years' time horizon (2013-2019).

Based on the graph, all the months show the same behavior over time, which reflects one of the limitations of the fixed-effects model, which assumes independence between observations. To consider the dependence and the hierarchical structure of the data, we add a random effect to the fixed-effects model, the model thus obtained is called a multilevel mixed-effects model.

- For temperature and radiation

$$
\mathbf{Y i j k m}=\beta \mathbf{0}+\beta \mathbf{1} * \mathbf{A}+\beta 2 * \mathbf{B}+\beta 3 * \mathbf{C}+\beta 4 * \mathbf{D}+\mathbf{b 0} \mathbf{i}+\mathbf{b 0}(\mathbf{j}) \mathbf{i}+\mathbf{b 0}(\mathbf{j k}) \mathbf{i}+\varepsilon \mathbf{i j k m}
$$

$\beta 0, \beta 1, \beta 2, \beta 3$ and $\beta 4$ represent the fixed effects. eijkm represents the random, the index i indicates the level 1 observations, $\mathrm{j}$ level 2 and $\mathrm{k}$ those of level 3, Tijkm is then the kth observation of the temperature/radiation variable for the day (i) in the month $(\mathrm{j})$ in the year $(\mathrm{k}), \beta 0$ represents the "standard" or average temperature/ radiation of a day at the starting time (Zero Time). The term b0i constitutes the random effect specifying the day $i$ associated with the intercept and representing the variations in the temperature/radiation of the day with respect to the start time. The term b0(j)i constitutes the random effect specifying the month $\mathrm{j}$ including the day $\mathrm{i}$ associated with the intercept. The term $\mathrm{b} 0(\mathrm{jk}) \mathrm{i}$ constitutes the random effect specifying the year $\mathrm{k}$ and month $\mathrm{j}$ including the day $\mathrm{i}$ associated with the intercept.

$\mathrm{A}=$ Time, $\mathrm{B}=$ Maxt, $\mathrm{C}=$ Mint $\& \mathrm{D}=$ rainfall.

- For precipitation

$$
\mathbf{T i j k}=\beta \mathbf{0}+\beta \mathbf{1} * \cos *(\mathbf{w X i j k}-\phi \mathbf{T})+\mathbf{b} 0 \mathbf{i}+\mathbf{b 0}(\mathbf{j}) \mathbf{i}+\varepsilon \mathbf{i j k}
$$

With: $\mathrm{w}=0.2, \phi \mathrm{T}=20, \mathrm{~T}$ and $\mathrm{X}$ are fixed, $\beta 0, \beta 1$ represent fixed effects. The parameters $\beta 0, \beta 1$ and $\sigma \varepsilon$ are estimated by the least squares method.

The subscripts $i$ and $j$ denote respectively the level 1 and 2 observations, Tijk is then the kth observation of the precipitation variable for month (i) in year (j), $\beta 0$ corresponds to the "standard" or average precipitation of a month at the starting time (time zero). The term b0i represents the random effect specifying month (i) associated with the $\beta 0$ intercept representing the months precipitation variations from the starting time. The term $b 0(j) i$ is the random effect specifying year $j$ including month i associated with the intercept $\beta 0 . \beta 1$ also represents the average increase in precipitation per unit time.

Soil data. A survey was carried out to collect both disturbed and undisturbed soil samples from the surface and subsurface horizons from wheat fields in the Rhamna province. Moreover, field measurement such as soil color determination was carried out by using a Munsell chart. Furthermore, in accordance with the soil data requirement for APSIM model, the physico-chemical soil properties were determined such as texture using a hydrometer according to the Bouyou $\cos ^{77}$ method; bulk density (BD) by the core method; soil moisture content by the gravimetric method; $\mathrm{pH}$-water by the potentiometric method; electrical conductivity (EC) using the EC meter in a 1:5 soil to water ratio; organic carbon $(\mathrm{OC})$ by the dry combustion; nitrate $\left(\mathrm{NO}_{3}^{-}\right)$\& ammonium $\left(\mathrm{NH}_{4}{ }^{+}\right)$by the scalar method and cation exchange capacity (CEC) by the cobaltihexamine method.

The study revealed that the soils of Rhamna are dominantly sandy clay loam, reddish brown in color, highly compacted soil due to a higher bulk density, alkaline $\mathrm{pH}$, non-saline, low in carbon, moderate in nitrogen and CEC (Table 1). 


\begin{tabular}{|c|c|c|c|c|c|c|c|c|c|c|c|c|c|}
\hline $\begin{array}{l}\text { Depth } \\
\text { (cm) }\end{array}$ & Clay (\%) & Silt (\%) & Sand (\%) & Texture & $\begin{array}{l}\text { Munsell } \\
\text { Color }\end{array}$ & $\mathrm{BD}\left(\mathrm{g} / \mathrm{cm}^{3}\right)$ & SMC (\%) & $\begin{array}{l}\mathrm{pH}(1: 5 \\
\text { water) }\end{array}$ & $\begin{array}{l}\text { EC (1:5 } \\
\text { dS/m) }\end{array}$ & OC (\%) & $\begin{array}{l}\mathrm{NO}_{3}{ }^{-}(\mathrm{kg} / \\
\text { ha) }\end{array}$ & $\begin{array}{l}\mathrm{NH}_{4}{ }^{+}(\mathrm{kg} / \\
\text { ha) }\end{array}$ & $\begin{array}{l}\text { CEC } \\
\text { (cmol + I } \\
\text { kg) }\end{array}$ \\
\hline $0-20$ & 20 & 22 & 58 & $\begin{array}{l}\text { Sandy Clay } \\
\text { Loam }\end{array}$ & $\begin{array}{l}\text { Reddish } \\
\text { Brown } \\
\text { (5YR 4/4) }\end{array}$ & 1.45 & 3.00 & 8.51 & 0.54 & 0.77 & 14.29 & 2.35 & 17.90 \\
\hline $20-50$ & 18 & 20 & 62 & $\begin{array}{l}\text { Sandy } \\
\text { Loam }\end{array}$ & $\begin{array}{l}\text { Reddish } \\
\text { Brown } \\
\text { (5YR 4/4) }\end{array}$ & 1.46 & 3.01 & 8.53 & 0.54 & 0.77 & 53.15 & 8.74 & 18.20 \\
\hline
\end{tabular}

Table 1. Soil physical and chemical properties of the Rhamna region.

Evaluation of the APSIM Model. Linear regression was used to compare graphically and to analyze statistically measured and predicted data of wheat yield, in order to evaluate the adaptability and the performance of the APSIM model. The statistical indices which are the coefficient of determination $\left(\mathbf{R}^{2}\right)$, the root mean square error (RMSE) [Eq. 4], the Nash-Sutcliffe efficiency (NSE) $)^{78}$ [Eq. 5] and the index of agreement (d) ${ }^{79}$ [Eq. 6], are defined as follows:

$$
\begin{gathered}
\mathbf{R M S E}=\left[\sum_{i=1}^{\mathrm{n}} \frac{\left(\mathrm{Y}_{\mathrm{i}}^{\text {obs }}-\mathrm{Y}_{\mathrm{i}}^{\text {sim }}\right)^{2}}{\mathrm{n}}\right]^{0.5} \\
\mathbf{N S E}=1-\frac{\sum_{\mathrm{i}=1}^{\mathrm{n}}\left(\mathrm{Y}_{\mathrm{i}}^{\text {obs }}-\mathrm{Y}_{\mathrm{i}}^{\text {sim }}\right)^{2}}{\sum_{\mathrm{i}=1}^{\mathrm{n}}\left(\mathrm{Y}_{\mathrm{i}}^{\text {obs }}-\mathrm{Y}^{\text {mean }}\right)^{2}} \\
\mathbf{d}=1-\frac{\sum_{\mathrm{i}=1}^{\mathrm{n}}\left(\mathrm{Y}_{\mathrm{i}}^{\text {obs }}-\mathrm{Y}_{\mathrm{i}}^{\text {sim }}\right)^{2}}{\sum_{\mathrm{i}=1}^{\mathrm{n}}\left(\left|\mathrm{Y}_{\mathrm{i}}^{\text {sim }}-\mathrm{Y}^{\text {mean }}\right|+\left|\mathrm{Y}_{\mathrm{i}}^{\text {obs }}-\mathrm{Y}^{\text {mean }}\right|\right)^{2}}
\end{gathered}
$$

where $\boldsymbol{Y i}^{\boldsymbol{s i m}}$ is the predicted value, $\boldsymbol{Y i}^{\boldsymbol{i b s}}$ is the observed value, $\boldsymbol{Y}^{\text {mean }}$ is the mean of the observed values and $\boldsymbol{n}$ is the number of observations.

For good model performance, values of RMSE [Eq. 4] should be close to 0, that indicate the better agreement between the two variables ${ }^{80}$. The agreement value of 1 indicates a perfect match of the simulated to the observed data for NSE [Eq. 5] ${ }^{78}$ and $\mathbf{d}$ [Eq. 6 ${ }^{81}$. Vice versa, 0 indicates no agreement for both.

Model validation. Various simulations for wheat yield were conducted by APSIM model Version 7.10 under natural rainfed conditions for Marzak cultivar, which is the common variety mostly used in the Rhamna region-Central Morocco. They were carried out using: (i) a daily weather data for 7 years (2013 to 2019), (ii) soil data, (iii) water balance parameters calculated and/or estimated as described by/in previous studies ${ }^{82-90}$, and (iv) growth and management crop data retrieved from the field survey. In fact, a calibration of the APSIM model was realized until obtaining a simulated wheat yield that fully matches with the measured wheat yield of Rhamna region, which were collected from the Regional Office for Agricultural Development of Haouz, Morocco (ORMVAH). Indeed, the projected climate data (2020 to 2030) which is realized by the statistical mixed model was integrated in the calibrated APSIM model to obtain the future scenarios of wheat yield. Therefore, different sowing dates were simulated using the calibrated APSIM model to analyze their effects on wheat yield. Wheat may be sown early due to the limitation of the available water, and it may be sown at a medium or late date due to delay in harvesting previous crops and/or rainfall. However, according to the regional sowing window, the sowing dates started on 25 October and were repeated every 10 days until 5 January. Moreover, several simulations with various varieties of wheat under the same conditions were analyzed to choose the most suitable cultivar for the region with high yield.

\section{Results}

Climate change scenarios. Adjustment of the model (2). The fitting of the second model gives the following results (Fig. 6):

According to the synthesis results, the p-value is lower than 0.05 for all parameters of the fixed effect of radiation, temperature and rain. Therefore, the obtained values for the random effect and error parameters agree.

Thus, to assert the validation of the model, we need to examine the fit of the fitted values and errors, and to check the normal distribution line: The points are well fitted by contribution to normality, and the samples follow the normal distribution by perfection. Thus, the measurement errors are also aligned in terms of mean (Figs. 7, $8,9)$. Therefore, the multilevel linear mixed effect model is suitable for the sample we want to treat.

Adjustment of the model (3).. Consistent with the simulation results, the p-value is also less than 0.05 for all precipitation fixed effect parameters (Fig. 10). Furthermore, the values obtained for the random effect and error parameters are consistent. 


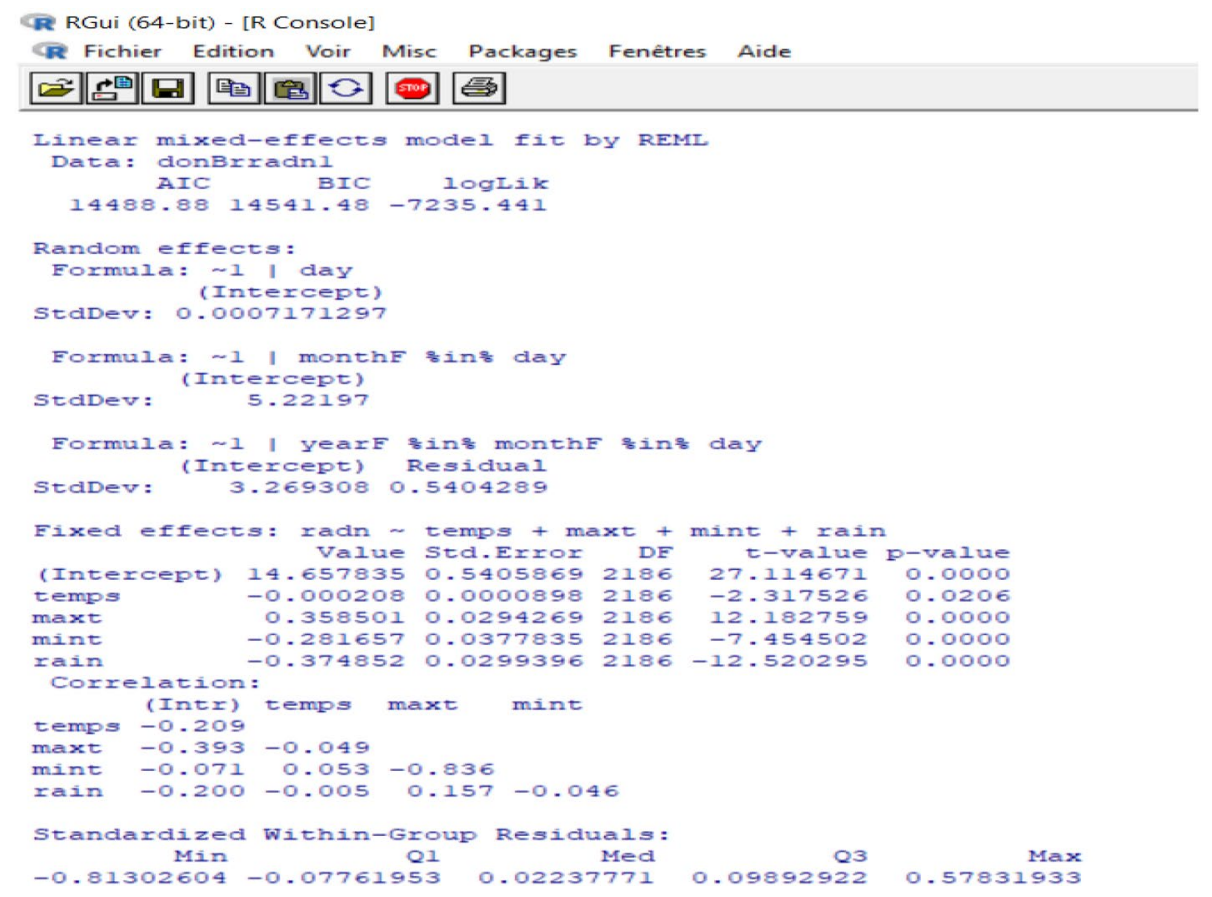

Figure 6. Summary of the model (2).

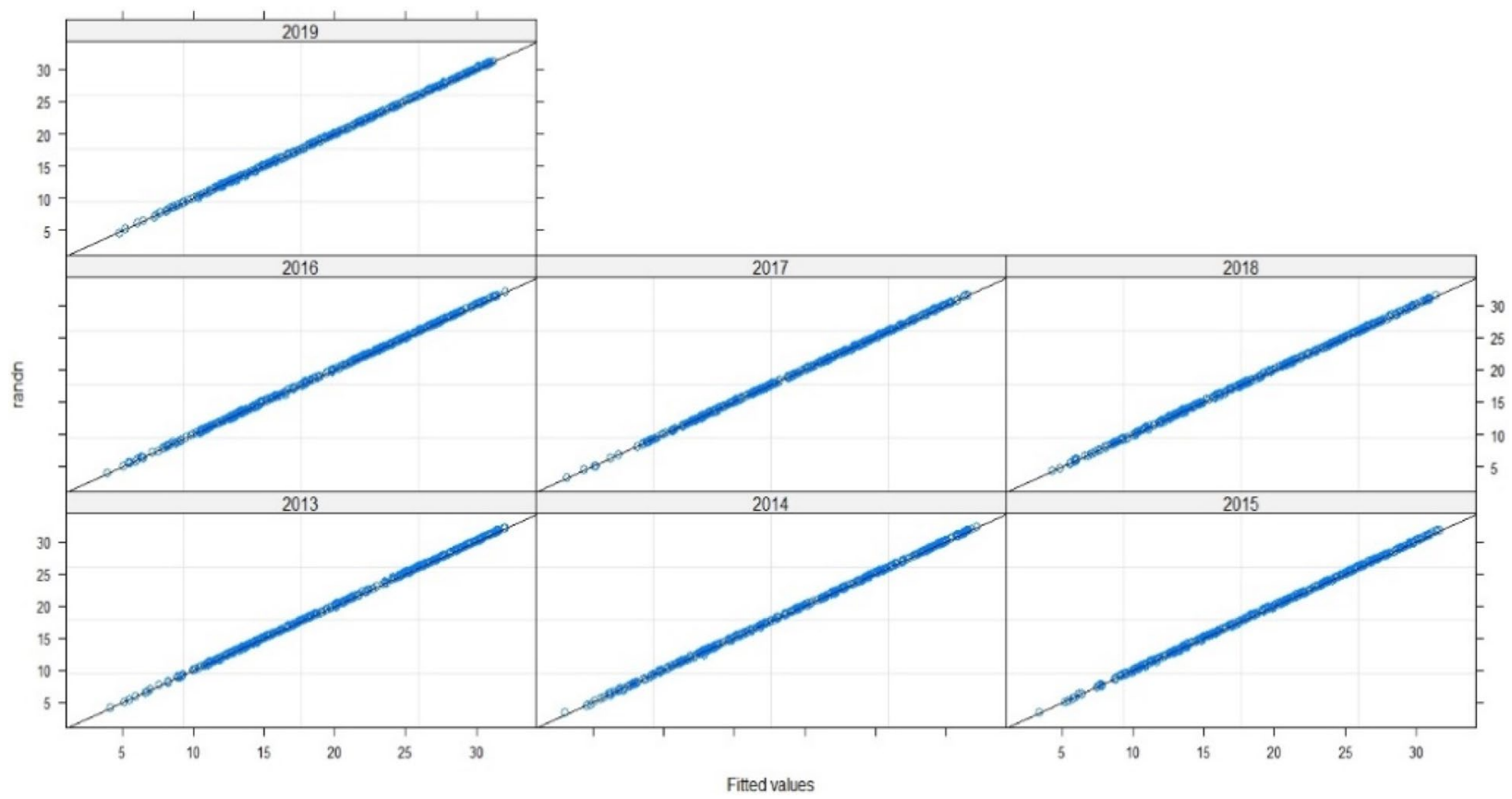

Figure 7. Radiation in terms of the adjusted values.

Furthermore, to affirm the validation of the model, we need to examine the fit of the fitted values and errors, and check the normal distribution line: The points are well fitted with respect to normality. Thus, the measurement errors are also aligned in terms of mean (Figs. 11, 12). Therefore, the multilevel linear mixed effect model is suitable for the sample we want to treat.

Future scenarios. The results of future scenarios for the Rhamna region from 2020 to 2030 showed that the mean annual rainfall is about $113 \mathrm{~mm}$, which is low in quantity and erratic in distribution as well. The lowest precipitation is obtained in June $(0.05 \mathrm{~mm})$, whereas the highest is in the month of November, which is $35.84 \mathrm{~mm}$ (Fig. 13). 


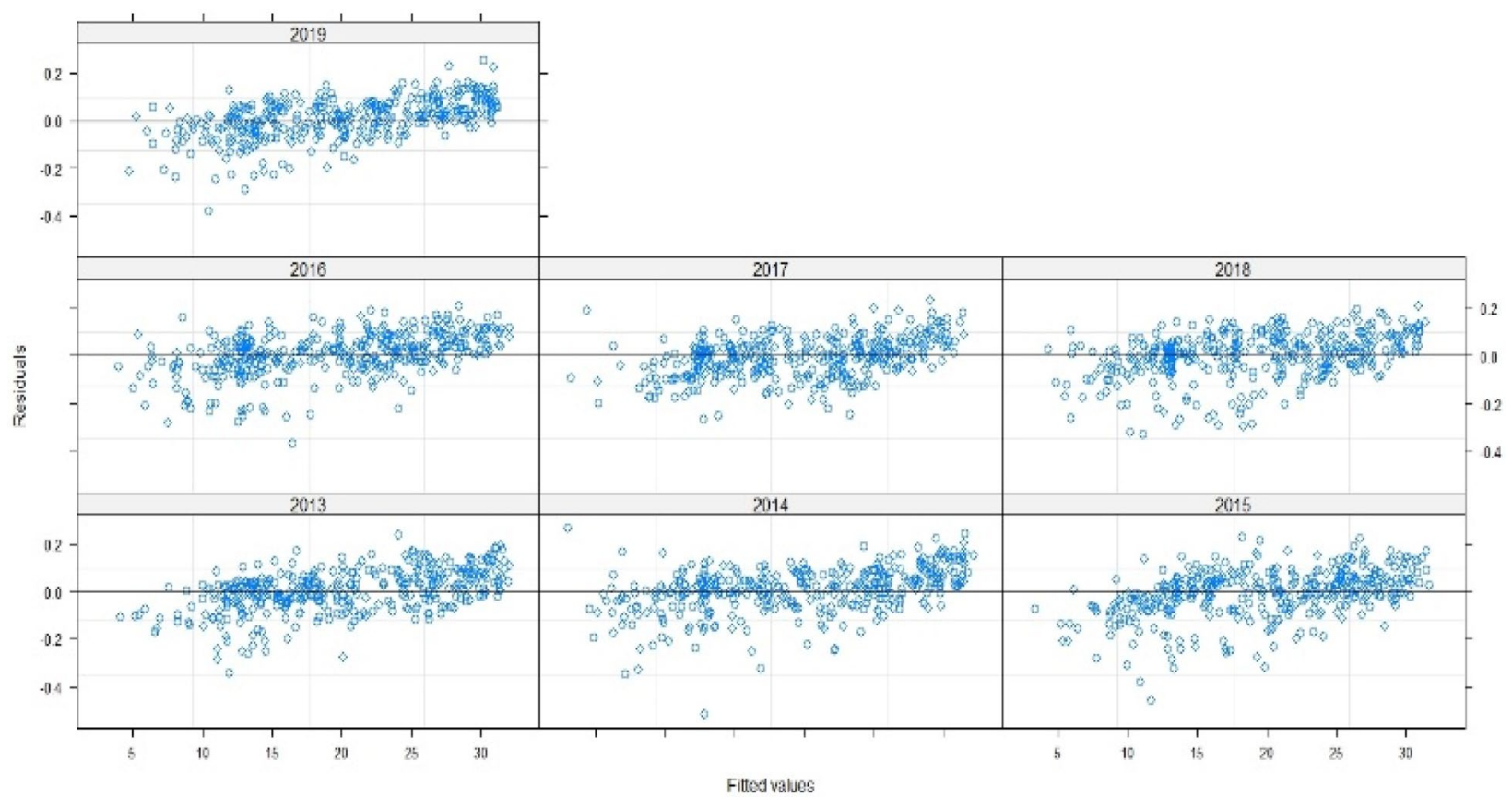

Figure 8. Errors in terms of the adjusted values.

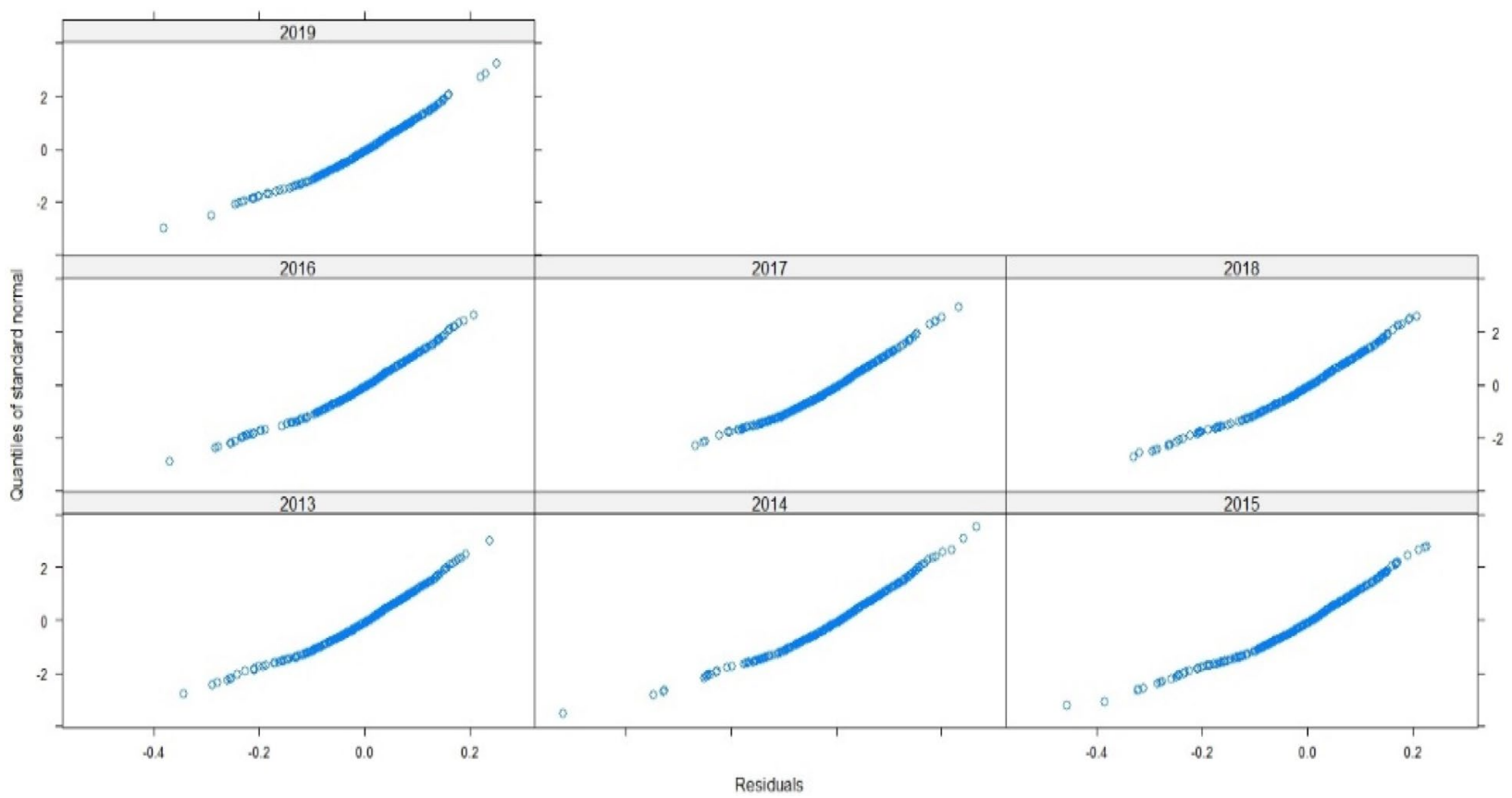

Figure 9. The standard Normal.

The annual average daily maximum and minimum temperature are $27.61{ }^{\circ} \mathrm{C}$ and $18.67{ }^{\circ} \mathrm{C}$, respectively. August is the hottest month of the year, with a maximum and minimum average daily temperature of $37.50{ }^{\circ} \mathrm{C}$ and $27.20^{\circ} \mathrm{C}$, respectively. January is therefore the coldest month of the year with a maximum and minimum average daily temperature in the range respectively of $18.86^{\circ} \mathrm{C}$ and $11.11^{\circ} \mathrm{C}$ (Fig. 14).

Figure 15 shows the daily solar radiation for the future years (2020-2030). The annual average daily solar radiation during this period is $18.61 \mathrm{MJ} / \mathrm{m}^{2}$. The highest monthly averaged radiation was detected in June with a value of $27.06 \mathrm{MJ} / \mathrm{m}^{2}$, and the lowest radiation was in December with a value of $10.09 \mathrm{MJ} / \mathrm{m}^{2}$.

Performance of APSIM model. To assess whether the model provided the right answer (wheat yield) for the right reasons, we compared the wheat yield measurements for 6 years to APSIM simulations output (Table 2; Fig. 16). Three parameters are found to be the most sensitive with the relative sensitivity values such as: 


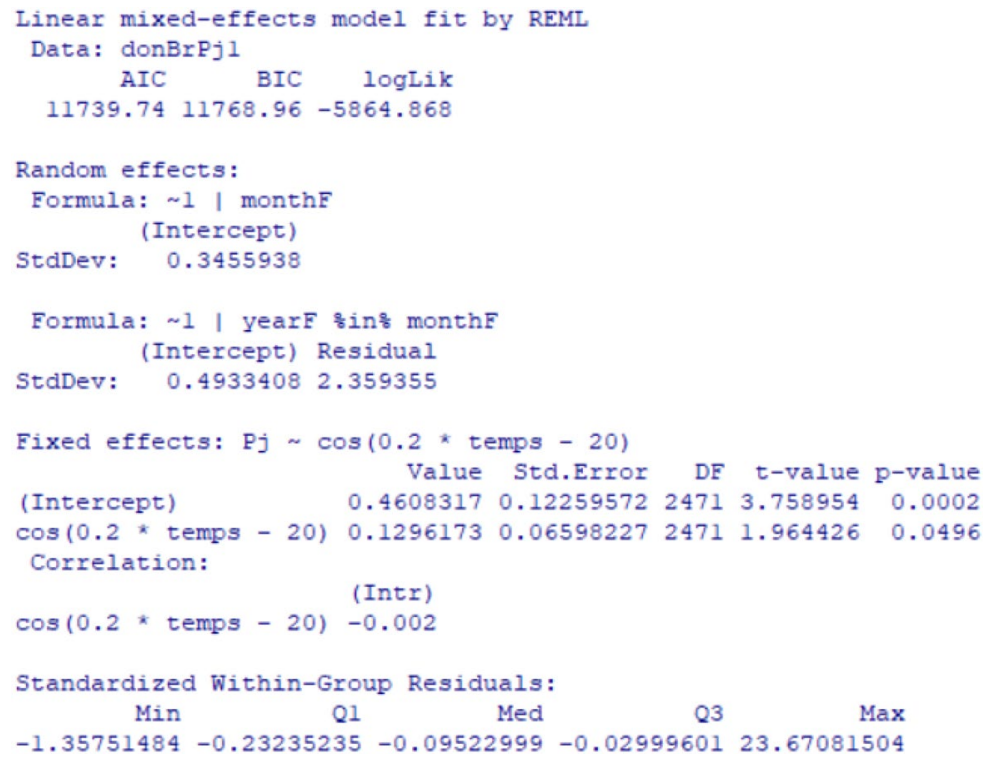

Figure 10. Summary of the model (3).

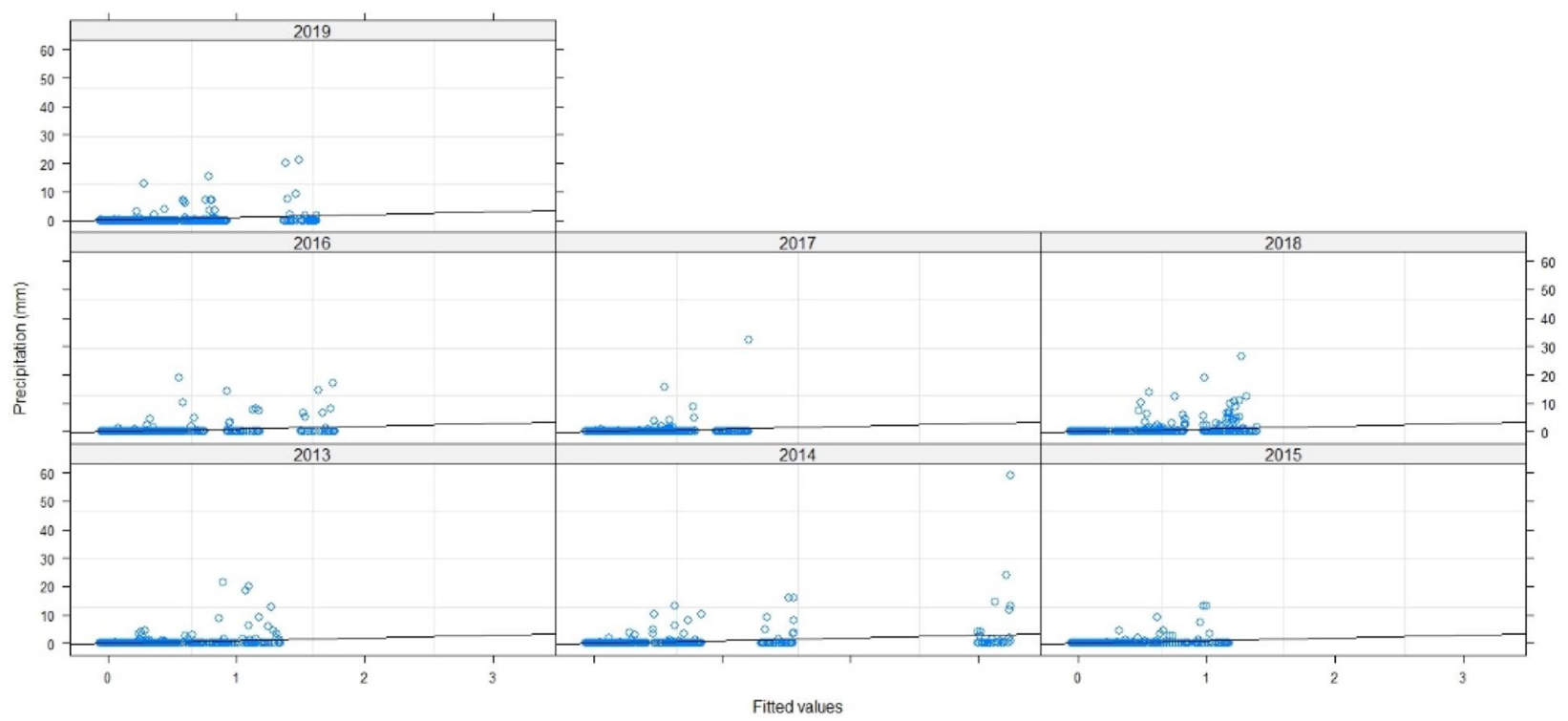

Figure 11. Precipitation in terms of the adjusted values.

photoperiod, vernalization and the initial fraction of plant available water capacity (PAWC). We found that after determining these three coefficients, the model predicted well the wheat yield in the Rhamna region-Central Morocco.

According to the performance criteria, the simulated data of wheat yield by APSIM model in comparison with the observed data allowed us to obtain a good model performance with very satisfactory values of RMSE, NSE and $d$ of the order of $0.13,0.95$ and 0.98 , respectively (Table 2; Fig. 16).

Therefore, the aforementioned indexes imply the robustness of the model in predicting wheat yield. They demonstrated that the APSIM-wheat model provided an excellent simulation performance during the determination of winter wheat yield for the Rhamna region. This indicates that the model can reflect the reality and provides a better estimation of the studied process.

Future scenarios for wheat yield. Various simulations were achieved using the calibrated APSIM model to estimate the wheat yield of Marzak cultivar for the future scenarios in the Rhamna region. The results show that the yield varies between 0 and $2.33 \mathrm{t} /$ ha throughout the study period (Fig. 17). The maximum yield was observed for the 2026-2027 season, and the minimum yield was observed for five seasons that are: 2019-2020, 2020-2021, 2022-2023, 2025-2026, 2029-2030. The two seasons, 2023-2024 and 2027-2028, show yields 


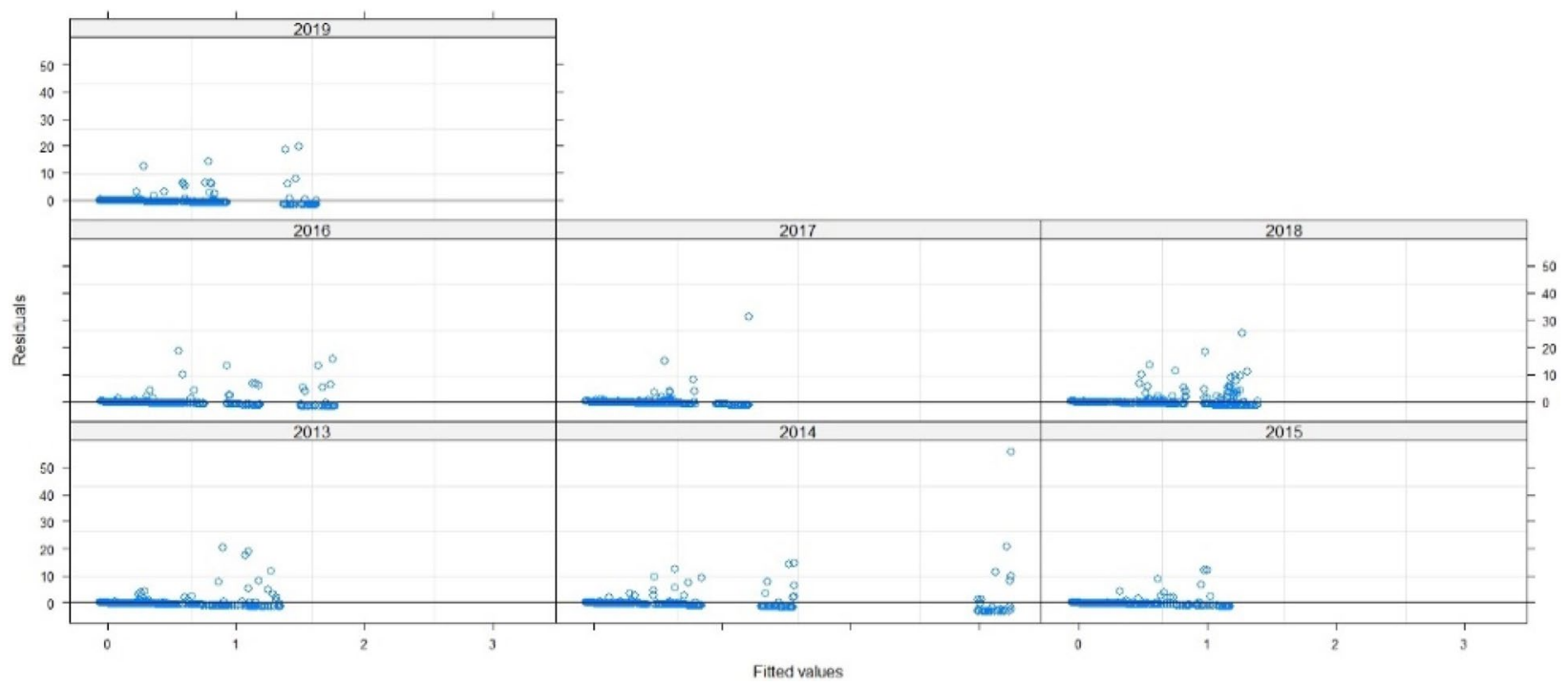

Figure 12. Errors in terms of the adjusted values.

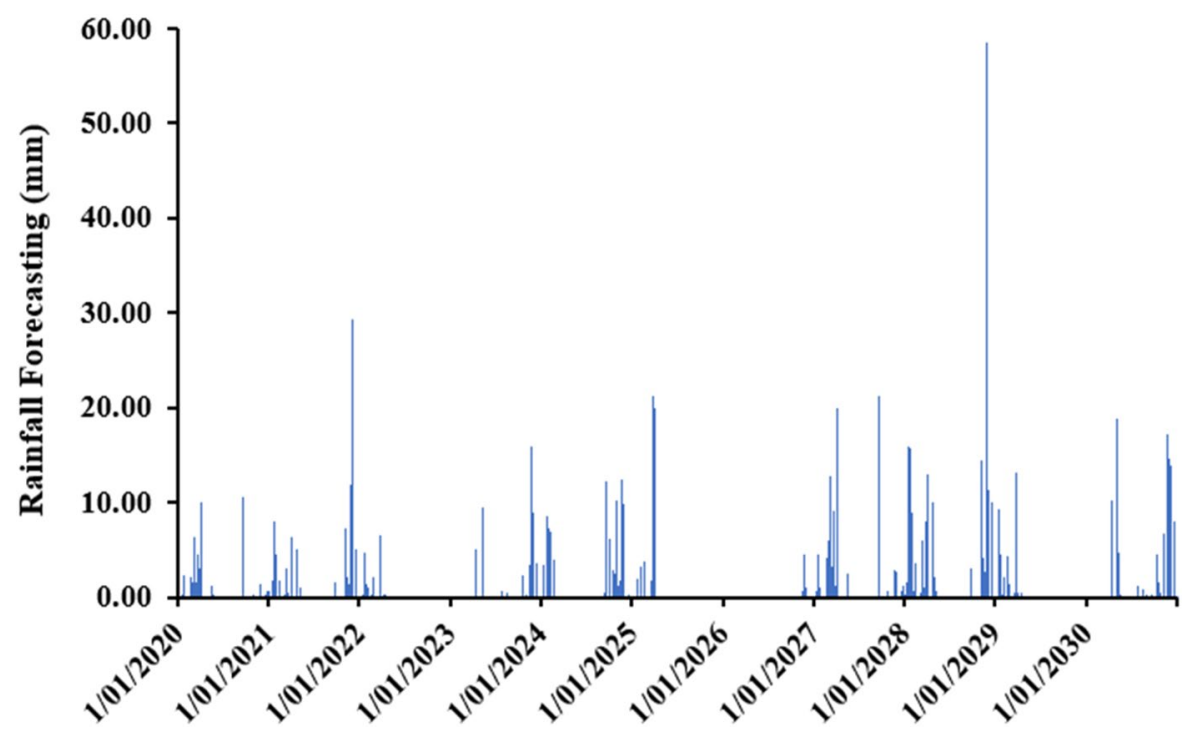

Figure 13. The evolution of rainfall over future years (2020-2030).

between 1 and $2 \mathrm{t} / \mathrm{ha}(1.14 \mathrm{t} / \mathrm{ha}$ and $1.50 \mathrm{t} / \mathrm{ha}$, respectively). The yields for the three last seasons (2021-2022, 2024-2025 and 2028-2029) are between 0 and $1 \mathrm{t} / \mathrm{ha}$ (0.54 t/ha, $0.91 \mathrm{t} / \mathrm{ha}$ and $0.70 \mathrm{t} / \mathrm{ha}$, respectively).

The seasons that present a zero or minimal yield are consistent with the seasons in which the rainfall is limited or insufficient. In general, the yield still not satisfactory since the area is characterized by a semi-arid climate.

Optimum sowing date of wheat. In the Rhamna region, there is no standard planting date, each farmer plants wheat crop on a date that suits him. Some of them are sown early, others during the medium or late period.

In this context, different simulation was carried out by the calibrated APSIM model to determine the optimum sowing date in the Rhamna region for the wheat crop, which was strongly affected by weather conditions and sowing date.

Figure 18 shows that the highest yield was simulated during the early and medium sowing date of agricultural seasons, which are 25 October and 25 November, respectively. The highest yields during early sowing date were observed in four seasons, which are: 2021-2022, 2024-2025, 2027-2028 and 2028-2029. Besides, the highest yields during medium sowing date were spotted in two seasons: 2023-2024 and 2026-2027.

The agricultural season of 2021-2022 ranged from 0.29 to $1.38 \mathrm{t} / \mathrm{ha}$, the highest and lowest yields were simulated for 25 October and 5 January sowing dates, respectively. Delaying the sowing date from 25 October to 5 January decreased yield of $1.09 \mathrm{t} / \mathrm{ha}$. Further, the maximum value brought about in an increase in yield of 0.84 $\mathrm{t} / \mathrm{ha}$ in comparison with the yield of the same season simulated by APSIM model.

Regarding the agricultural season of 2024-2025, the yields varied from 0.76 to $2.32 \mathrm{t} /$ ha which were predicted for 5 January and 25 October, respectively. The yield decreased by approximately $1.56 \mathrm{t} / \mathrm{ha}$, with a delay in the 


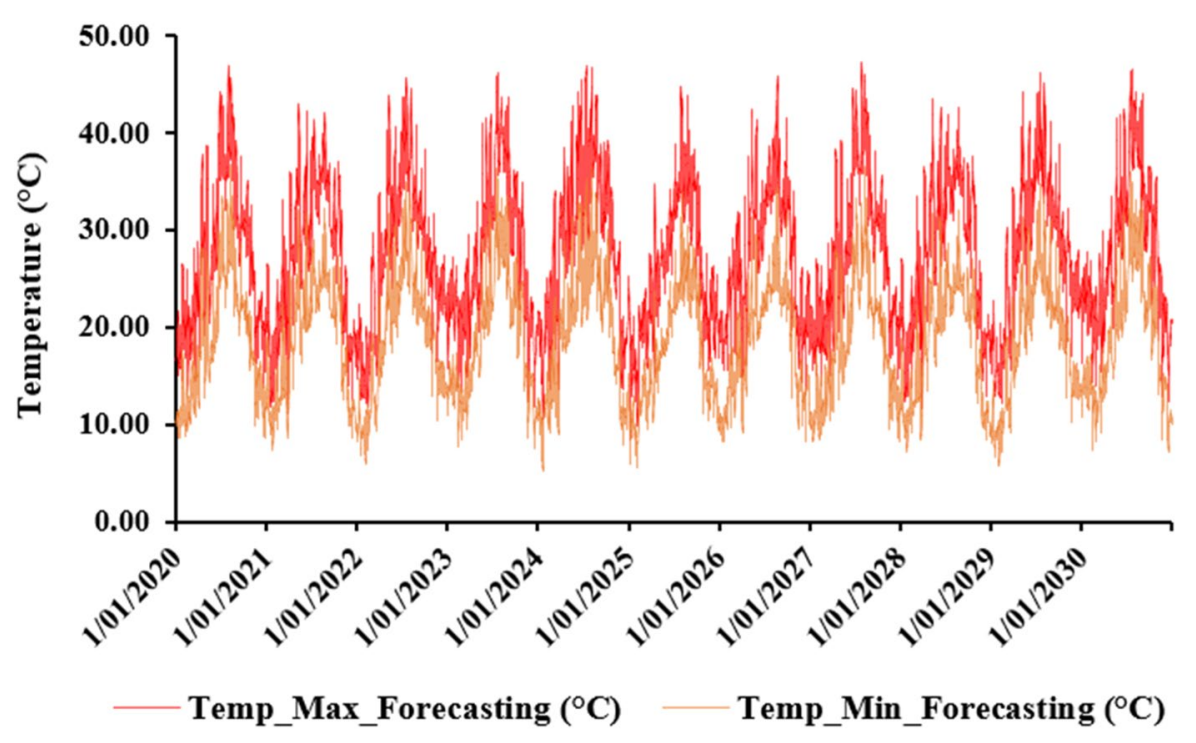

Figure 14. The evolution of maximum and minimum temperature over future years (2020-2030).

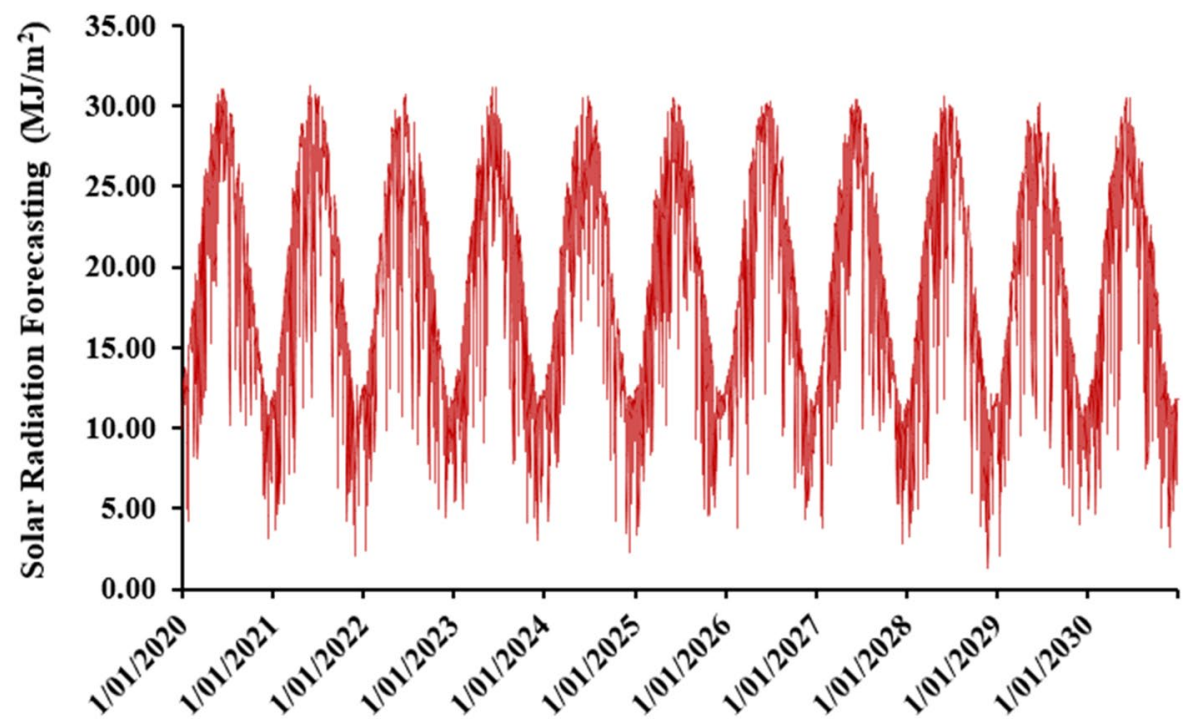

Figure 15. The evolution of solar radiation over future years (2020-2030).

\begin{tabular}{|l|l|l|}
\hline \multirow{2}{*}{ Cropping year } & \multicolumn{2}{|l|}{ Grain yield (t/ha) } \\
\cline { 2 - 3 } & Measured & Simulated \\
\hline $2013-2014$ & 1.66 & 1.44 \\
\hline $2014-2015$ & 0.26 & 0.27 \\
\hline $2015-2016$ & 0.05 & 0.00 \\
\hline $2016-2017$ & 1.06 & 1.27 \\
\hline $2017-2018$ & 0.45 & 0.35 \\
\hline $2018-2019$ & 0.02 & 0.00 \\
\hline Index & \multicolumn{2}{|l}{} \\
\hline$R^{2}$ & 0.95 \\
\hline RMSE & 0.13 \\
\hline NSE & 0.95 \\
\hline$d$ & 0.98 \\
\hline
\end{tabular}

Table 2. Statistical indices of assessing the performance of APSIM-Wheat model in predicting grain yield. 


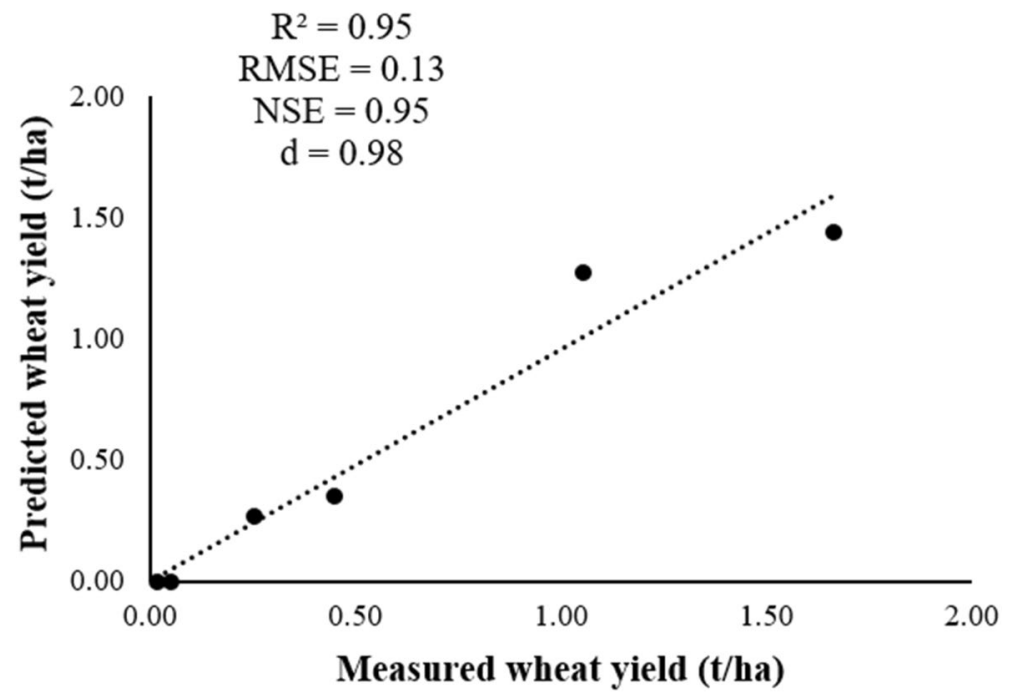

Figure 16. Predicted versus measured wheat yield of Marzak cultivar.

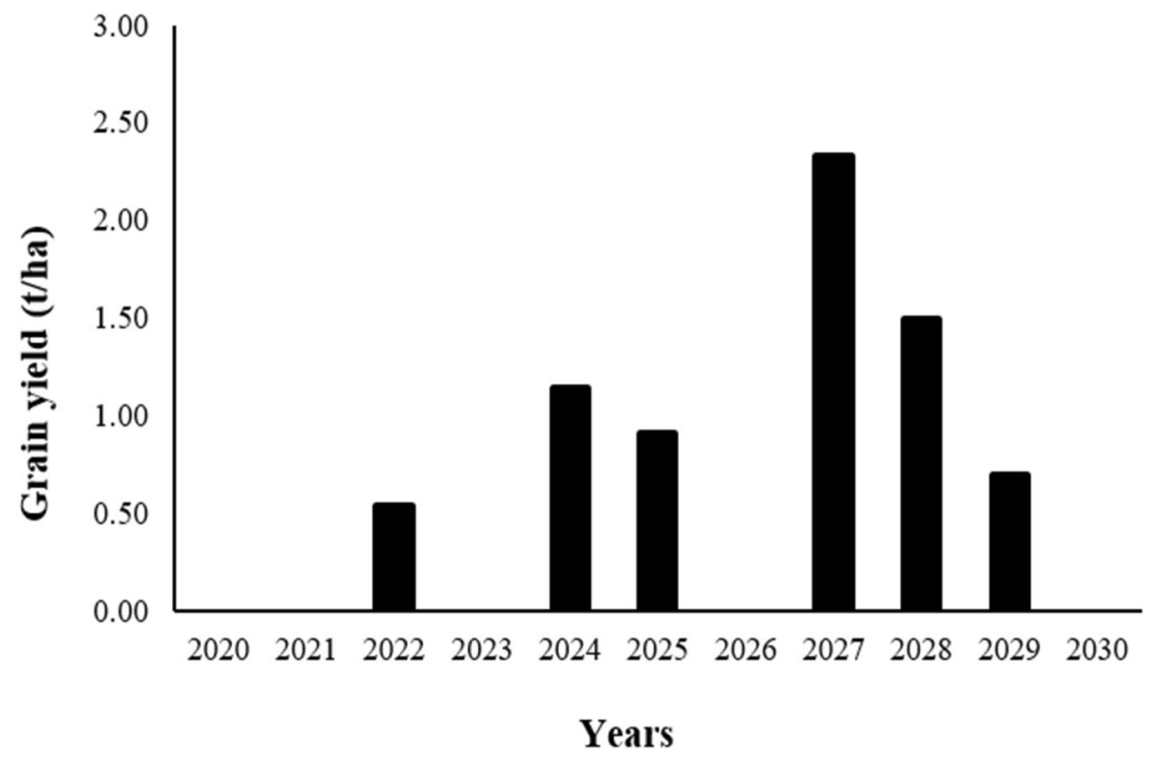

Figure 17. Future scenarios for wheat yield in the Rhamna region.

sowing date from 25 October to 5 January. In addition, the maximum value brought about an increase in yield of about $1.41 \mathrm{t} / \mathrm{ha}$ in comparison with the yield of the same year.

Concerning the year of 2027-2028, the yield ranged from 0.10 to $2.05 \mathrm{t} / \mathrm{ha}$. The lowest yield was noticed through sowing on 5 January, and the highest yield through sowing on 25 October. Delay in sowing date from 25 October to 5 January has resulted in a decrease in yield with about $1.95 \mathrm{t} / \mathrm{ha}$. Besides, the maximum yield obtained showed an increase in comparison with the yield of the same year with a value of $0.55 \mathrm{t} / \mathrm{ha}$.

Relating to the average predicted yield for the year of 2028-2029, it varied from 0.32 to $1.69 \mathrm{t} / \mathrm{ha}$. Minimum and maximum yields were simulated for 5 January and 25 October sowing dates, respectively. Delay in sowing date from 25 October to 5 January resulted in a yield diminution of about $1.37 \mathrm{t} /$ ha. Furthermore, the maximum yield obtained showed an increase in comparison with the yield of the same season with a value of $0.99 \mathrm{t} / \mathrm{ha}$.

Otherwise, the agricultural season of 2023-2024 ranged from 0.40 to $1.17 \mathrm{t} / \mathrm{ha}$, the highest and lowest yields were simulated for 25 November and 5 January sowing dates, respectively. Delaying the sowing date from 25 November to 5 January decreased yield of $0.77 \mathrm{t} / \mathrm{ha}$. In addition, the maximum value brought about an increase in yield of $0.03 \mathrm{t} / \mathrm{ha}$ in comparison with the yield of the same season simulated by the APSIM model.

Moreover, the agricultural season of 2026-2027 varied from 0.78 to $2.72 \mathrm{t} /$ ha which were predicted for 5 January and 25 November, respectively. The yield decreased by approximately $1.94 \mathrm{t} / \mathrm{ha}$, with a delay in the sowing 

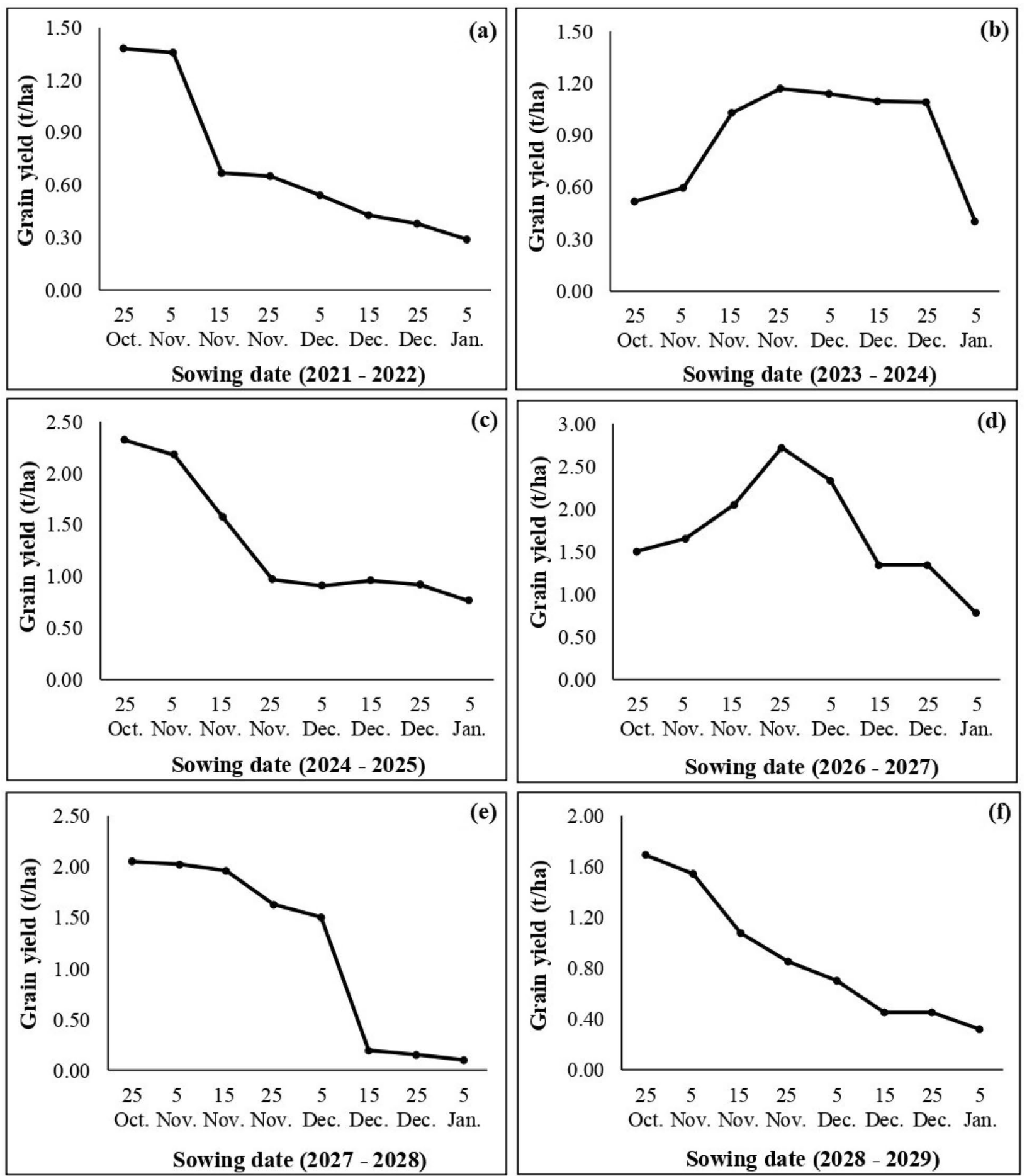

Figure 18. Predicted yield for different sowing dates of Marzak cultivar for the future scenarios.

date from 25 November to 5 January. Also, the maximum value resulted in an increase in yield of about $0.39 \mathrm{t} /$ ha in comparison with the yield of the same season.

On the other hand, the four seasons that are 2020-2021, 2022-2023, 2025-2026 and 2029-2030 do not give significant results because they corresponded to years of drought, especially during the growing period, which led to multiple impacts on wheat yield.

Wheat varieties. After the calibration of the APSIM model, different scenarios were carried out under the same conditions by comparing the yield of other varieties with the yield of the Marzak cultivar used in the Rhamna region.

The varieties which exhibited maximum values compared to the Marzak variety are presented in Fig. 19 during the calibration period, and in Fig. 20 during the future scenarios period. 


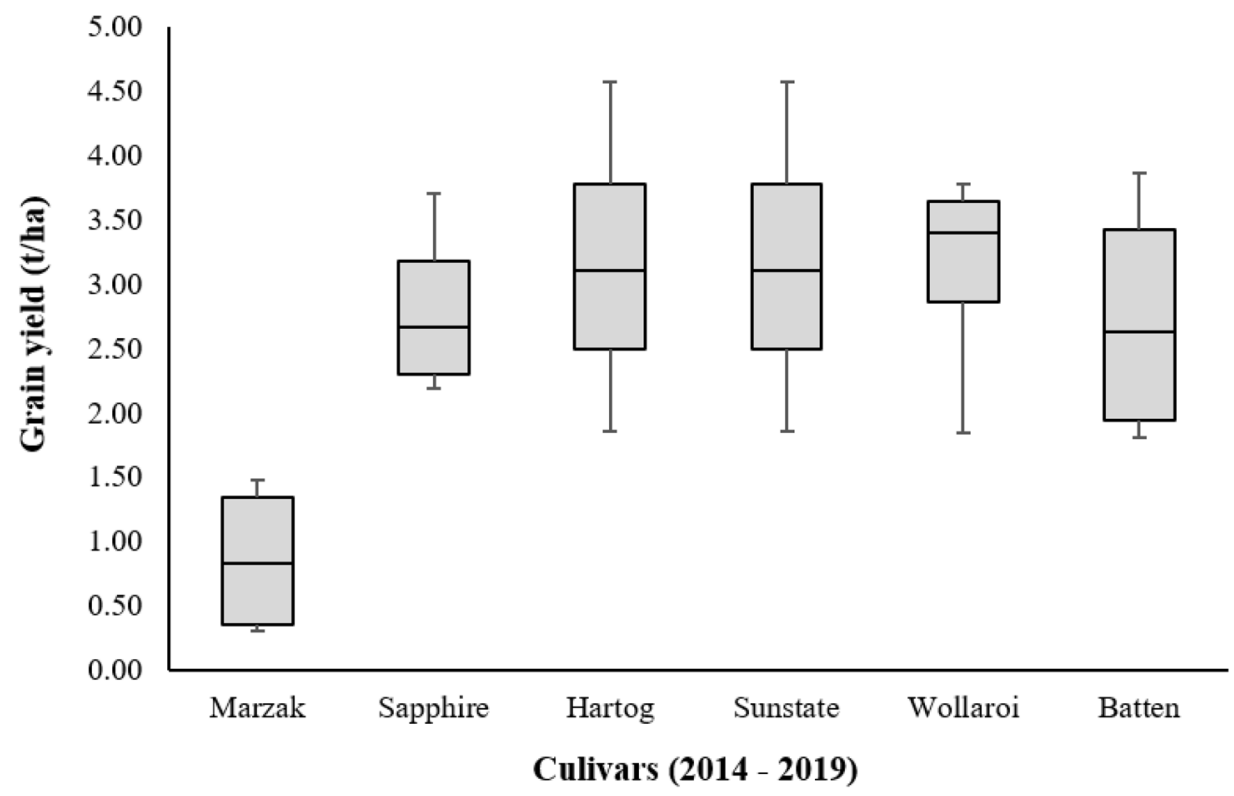

Figure 19. Comparison of several varieties simulated at the same conditions of the study area for the calibrated period (2014-2019).

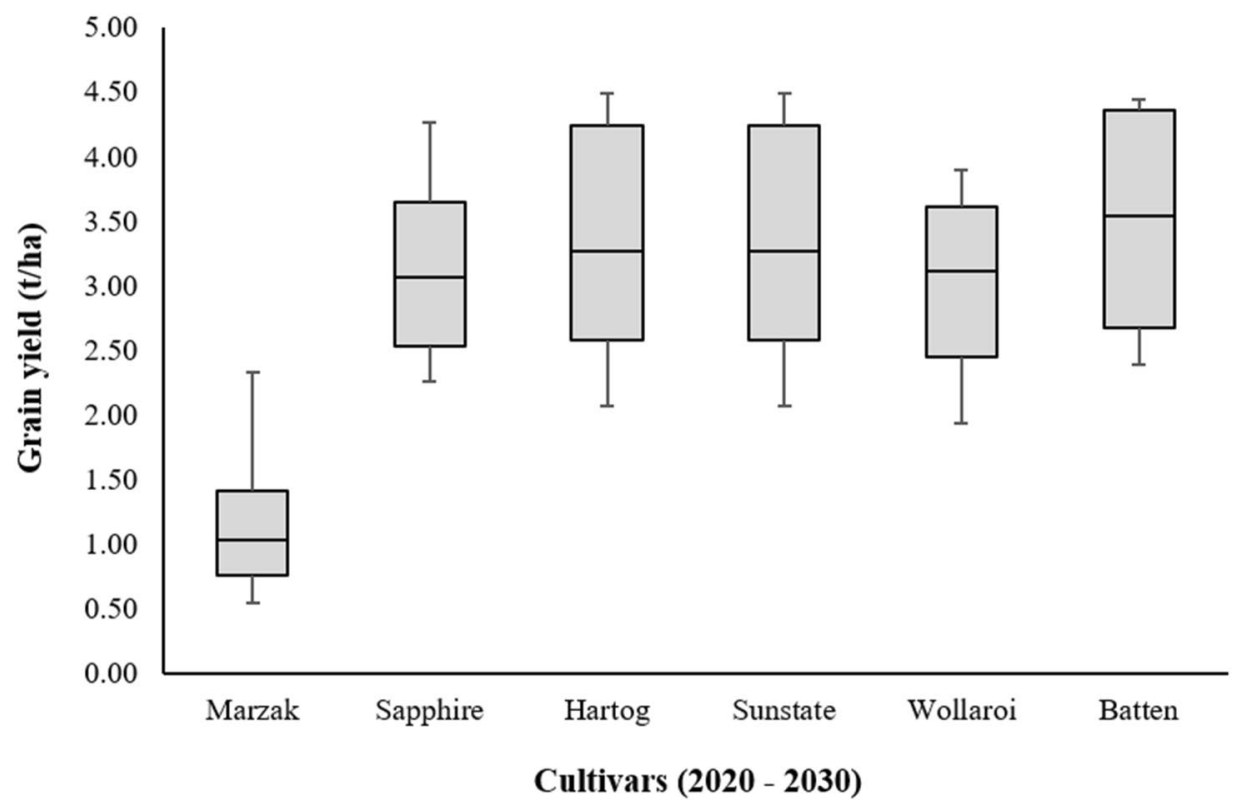

Figure 20. Comparison of several varieties simulated at the same conditions of the study area for the future scenarios (2020-2030).

The maximum value resulted from scenarios of cultivars for the calibration period (Fig. 19) was observed on two varieties of wheat, which are Hartog and Sunstate. The minimum and maximum value for the two cultivars varied from 1.86 to $4.57 \mathrm{t} /$ ha, respectively. The highest and lowest yield was increased by values of $3.13 \mathrm{t} / \mathrm{ha}$ and $1.55 \mathrm{t} / \mathrm{ha}$ compared to Marzak cultivar, respectively. Also, the Batten variety ranged from 1.81 to $3.86 \mathrm{t} / \mathrm{ha}$. These values show an increase of 1.5 and $2.42 \mathrm{t} / \mathrm{ha}$, respectively. Regarding Wollaroi, it varied between 1.84 and 3.78 $\mathrm{t} /$ ha, which shows an increase of 1.53 and $2.34 \mathrm{t} /$ ha, respectively. Moreover, Sapphire reaches maximum values relative to the crop used in the region which ranged between 2.19 and $3.71 \mathrm{t} /$ ha. These values show an increase of 1.88 and $2.27 \mathrm{t} / \mathrm{ha}$, respectively.

Similarly, as calibration period, Hartog and Sunstate cultivars show also maximum value during the future scenarios period (Fig. 20). The minimum and maximum value for the two cultivars varied from 2.07 to $4.49 \mathrm{t} /$ ha, respectively. The highest and lowest yield was increased by values of $2.16 \mathrm{t} / \mathrm{ha}$ and $1.53 \mathrm{t} / \mathrm{ha}$ compared to 
Marzak cultivar, respectively. As regards the Batten variety, it ranged from 2.39 to $4.44 \mathrm{t} / \mathrm{ha}$. These values show an increase of 1.85 and $2.11 \mathrm{t} / \mathrm{ha}$, respectively. Furthermore, Sapphire cultivar varied between 2.25 and $4.26 \mathrm{t} / \mathrm{ha}$. These values show an increase of 1.71 and $1.93 \mathrm{t} / \mathrm{ha}$, respectively. Furthermore, Wollaroi variety ranged between 1.93 and $3.90 \mathrm{t} / \mathrm{ha}$, which shows an increase of 1.39 and $1.57 \mathrm{t} / \mathrm{ha}$, respectively.

These results showed us that the use of one of these varieties in the Rhamna region instead of Marzak cultivar could lead to a very satisfactory increase in wheat yield.

\section{Discussion}

Our results showed that APSIM-Wheat model can be used as a suitable tool to investigate farm productivity thru building various scenarios management options for optimizing wheat yield under water limited environment. The ability of APSIM-Wheat model to predict yield in the semi-arid environment was confirmed by previous studies $^{91-95}$. Application of APSIM-Wheat for grain yield simulation showed reasonable predictive results not only in semi-arid climate (3,46,96-99 $^{\text {, but also in } \text { arid }^{44,45,100} \text { and Mediterranean }}{ }^{41,42,101-103}$ environments.

Determining future projections of climate data ${ }^{71-76}$ and integrating them into the APSIM model allowed us to get future scenarios of wheat yield in the study area. However, low yield was obtained comparing it with previous years due to either insufficient or absence of rainfall. The production of cereals in the semi-arid areas of Morocco, such as in other regions with the same climatic conditions, is strongly affected by inadequate or poorly distributed rainfall ${ }^{11,104}$. The upsurge of minimum/maximum temperature has been noticed during the recent decades ${ }^{105}$. The rise of temperature in the future years will lead to global warming thereby exasperating the drought incidence and affecting the precipitation pattern. This trend of climate variability justifies that the damage to agriculture and water scarcity has already been started and will be proliferated further over the next few years. Similar projections were reported on future climate which carried out using various climate models including multilevel mixed-effects model in the Moroccan context $t^{74,106-111}$, as well as Northern Africa ${ }^{112-114}$.

For this reason, various simulations were done to determine the optimum sowing date for the moisture deific area of Morocco. Accordingly, the simulated result confirmed that the yield obtained from plots seeded between 25 October and 25 November was higher than that sown until 05 January. The relationship between grain yield and different sowing dates of wheat are linear. The highest Predicted grain yield was obtained when it is sown in early sowing (i.e., late October) or medium sowing (i.e., late November), and decreased thereafter. The lowest grain yield was obtained in late sowing (January). This coincides with the findings of researches which affirmed that both early and medium sowing were beneficial for obtaining a highest yield, but the early sowing was more favorable to increase the wheat yield ${ }^{21-26}$. In addition, the results of predictions of the effect of sowing date on wheat yield using APSIM model were also consistent with many of the findings of simulations using other crop models in the semi-arid environment ${ }^{34,115-118}$. Therefore, extended life duration and favorable temperature especially at the grain filling stage, might be the main reason for the higher grain yield in early sowing dates ${ }^{43,119,120}$. While, delaying the sowing date beyond the optimum sowing date led to reduced grain yield, due to a shorter vegetative growth period of wheat ${ }^{115,121}$. Thus, sowing at the appropriate time can enhance the effective accumulative temperature, prolong the effective growth period of wheat, and then increase the yield ${ }^{122-124}$.

On the other hand, other simulations were performed using the calibrated APSIM model to test other types of cultivars, and then analyze and compare their yields with the yield of Marzak cultivars under the same conditions. From several varieties, Hartog, Sunstate, Wollaroi, Batten and Sapphire presented the highest yields in comparison with the Marzak variety. These significant results were observed for both periods, the calibration period and the future scenarios period. However, Sunstate and Hartog are the most cultivars adopted in arid and semi-arid regions, and widely used in these environments for many reasons: (i) very adequate for dry growing season, (ii) slow variety with excellent yield potential, (iii) did not suffer grain yield or grain quality losses, (iv) and possess a large resistance to herbicides and root $\operatorname{rot}^{125-130}$. Moreover, Batten and Sapphire are among the best performing varieties and among the earlier sown crops with highest yielding in arid and semi-arid climate ${ }^{131,132}$ but not suitable for the humid and sub-humid regions ${ }^{133-135}$. Furthermore, Wollaroi cultivar also performs well in drier areas, reputed for its high grain quality, tolerance to weathering, and resistance to crown rot and stripe rust $^{136-140}$. This indicates that these cultivars are suitable and appropriate for our situation, and the import and the seed of them increase and enhance the wheat yield in the Rhamna region.

\section{Conclusion}

Famers in Morocco continue growing wheat although its productivity is challenged by low and erratic precipitation; hot temperature; poor soil fertility and others. Seemingly, these production factors will aggravate in the years to come due to climate change. This study concluded that the use of APSIM model can help in evaluating the suitability of Central Morocco for wheat production. Based on this model, suitable time window for sowing and promising wheat varieties were identified that can be grown well in water deficit areas. This study recommends undertaking additional research taking into account varieties, sowing date, supplemental irrigation and nutrient and best management practices under water stressed environment. Yet, cultivar, sowing time and climate are found to be the critical factors for wheat growth hence they should be well managed.

Received: 16 July 2021; Accepted: 22 November 2021

Published online: 30 November 2021

\section{References}

1. FAO. Food and Agriculture Organization of the United Nations. FAOSTAT Data; www.faostat.fao.org (last access 15.06.21), (2016). 
2. Gomez, D., Salvador, P., Sanz, J. \& Casanova, J. L. Modelling wheat yield with antecedent information, satellite and climate data using machine learning methods in Mexico. Agric. For. Meteorol. 300, 108317. https://doi.org/10.1016/j.agrformet.2020.108317 (2021).

3. Wrigley, C. W. Wheat: A unique grain for the world. In Wheat chemistry and technology 4 th edn (eds Khan, K. \& Shewry, P. R.) 1-17 (AACC Int. Inc, St Paul, 2009).

4. Awika, J. M. Major cereal grains production and use around the world. In Advances in Cereal Science: Implications to Food Processing and Health Promotion, Vol. 1089 (eds Awika, J. M., Piironen, V. \& Bean, S.) 1-13 (American Chemical Society, 2011).

5. Gupta, R., Meghwal, M. \& Prabhakar, P. K. Bioactive compounds of pigmented wheat (Triticum aestivum): Potential benefits in human health. Trends Food Sci. Technol. 110, 240-252. https://doi.org/10.1016/j.tifs.2021.02.003 (2021).

6. FAO. Food and Agriculture Organization of the United Nations. FAOSTAT Data; www.faostat.fao.org (last access 15.06.21), (2020).

7. USDA. Grain and Feed Annual. United States Department of Agriculture (USDA), Foreign Agricultural Service (FAS), MO20200007; https://www.fas.usda.gov/data/morocco-grain-and-feed-annual-3 (last access 15.06.21), (2020).

8. McIntyre, C. L. et al. Molecular detection of genomic regions associated with grain yield and yield-related components in an elite bread wheat cross evaluated under irrigated and rainfed conditions. Theor. Appl. Genet. 120, 527-541. https://doi.org/10. 1007/s00122-009-1173-4 (2010).

9. UN. World population prospects. United Nations (UN), Department of Economic and Social Affairs (DESA); https://www.un. org/development/desa/en/news/population/world-population-prospects-2017.html (last access 15.06.21), (2017).

10. Gomez-Macpherson, H. \& Richards, R. A. Effect of sowing time on yield and agronomic characteristics of wheat in south-eastern Australia. Aust. J. Agric. Res. 46, 1381-1399. https://doi.org/10.1071/AR9951381 (1995).

11. Stone, P. J. \& Nicolas, M. E. Effect of timing of heat stress during grain filling on two wheat varieties differing in heat tolerance. I. Grain growth. Aust. J. Plant Physiol. 22, 927-934. https://doi.org/10.1071/PP9950927 (1995).

12. Mahdi, L., Bell, C. J. \& Ryan, J. Establishment and yield of wheat (Triticum turgidum L.) after early sowing at various depths in a semi-arid Mediterranean environment. Field Crops Res. 58, 187-196. https://doi.org/10.1016/S0378-4290(98)00094-X (1998).

13. Radmehr, M., Ayeneh, G. A. \& Mamghani, R. Responses of late, medium and early maturity bread wheat genotypes to different sowing date. I. Effect of sowing date on phonological, morphological, and grain yield of four breed wheat genotypes. Iran. J. Seed. Sapling 21, 175-189 (2003).

14. Turner, N. C. Agronomic options for improving rainfall use efficiency of crops in dryland farming systems. J. Exp. Bot. 55, 2413-2425. https://doi.org/10.1093/jxb/erh154 (2004).

15. Pickering, P. A. \& Bhave, M. Comprehensive analysis of Australian hard wheat cultivars shows limited puroindoline allele diversity. Plant Sci. 172, 371-379. https://doi.org/10.1016/j.plantsci.2006.09.013 (2007).

16. Zheng, B., Chenu, K., Fernanda Dreccer, M. \& Chapman, S. C. Breeding for the future: What are the potential impacts of future frost and heat events on sowing and flowering time requirements for Australian bread wheat (Triticum aestivium) varieties?. Glob. Change Biol. 18, 2899-2914. https://doi.org/10.1111/j.1365-2486.2012.02724.x (2012).

17. Wu, X. S., Chang, X. P. \& Jing, R. L. Genetic insight into yield-associated traits of wheat grown in multiple rain-fed environments. PLOS ONE 7, e31249. https://doi.org/10.1371/journal.pone.0031249 (2012).

18. Mueller, B. et al. Lengthening of the growing season in wheat and maize producing regions. Weather Clim. Extrem. 9, 47-56. https://doi.org/10.1016/j.wace.2015.04.001 (2015).

19. Hunt, J. R., Hayman, P. T., Richards, R. A. \& Passioura, J. B. Opportunities to reduce heat damage in rainfed wheat crops based on plant breeding and agronomic management. Field Crops Res. 224, 126-138. https://doi.org/10.1016/j.fcr.2018.05.012 (2018).

20. Ababaei, B. \& Chenu, K. Heat shocks increasingly impede grain filling but have little effect on grain setting across the Australian wheatbelt. Agric. For. Meteorol. 284, 107889. https://doi.org/10.1016/j.agrformet.2019.107889 (2020).

21. Anderson, W. K. \& Smith, W. R. Yield advantage of two semi-dwarf compared with two tall wheats depends on sowing time. Aust. J. Agric. Res. 41, 811-826. https://doi.org/10.1071/AR9900811 (1990).

22. Connor, D. J., Theiveyanathan, S. \& Rimmington, G. M. Development, growth, water-use and yield of a spring and a winter wheat in response to time of sowing. Aust. J. Agric. Res. 43, 493-516. https://doi.org/10.1071/AR9920493 (1992).

23. Owiss, T., Pala, M. \& Ryan, J. Management alternatives for improved durum wheat production under supplemental irrigation in Syria. Eur. J. Agron. 11, 255-266. https://doi.org/10.1016/S1161-0301(99)00036-2 (1999).

24. Bassu, S., Asseng, A., Motzo, R. \& Giunta, F. Optimizing sowing date of durum wheat in a variable Mediterranean environment. Field Crops Res. 111, 109-118. https://doi.org/10.1016/j.fcr.2008.11.002 (2009).

25. Bannayan, M., Eyshi Rezaei, E. \& Hoogenboom, G. Determining optimum sowing dates for rainfed wheat using the precipitation uncertainty model and adjusted crop evapotranspiration. Agric. Water Manag. 126, 56-63. https://doi.org/10.1016/j.agwat. 2013.05.001 (2013).

26. Liang, Y. F. et al. Subsoiling and sowing time influence soil water content, nitrogen translocation and yield of dryland winter wheat. Agronomy 9, 37. https://doi.org/10.3390/agronomy9010037 (2019).

27. Farooq, M., Basra, S. M. A., Rehman, H. \& Saleem, B. A. Seed priming enhances the performance of late sown wheat (Triticum aestivum L.) by improving chilling tolerance. J. Agron. Crop Sci. 194, 55-60. https://doi.org/10.1111/j.1439-037X.2007.00287.x (2008).

28. Kudair, I. M. \& Adary, A. H. The effects of temperature and planting depth on coleoptile length of some Iraqi local and introduced wheat cultivars. Mesopotamia J. Agric. 17, 49-62 (1982).

29. Leoncini, E. et al. Phytochemical profile and nutraceutical value of old and modern common wheat cultivars. PLoS ONE 7 , e45997. https://doi.org/10.1371/journal.pone.0045997 (2012).

30. Busko, M. et al. The effect of Fusarium inoculation and fungicide application on concentrations of flavonoids (apigenin, kaempferol, luteolin, naringenin, quercetin, rutin, vitexin) in winter wheat cultivars. Am. J. Plant Sci. 5, 3727-3736. https://doi.org/10. 4236/ajps.2014.525389 (2014).

31. Bannayan, M., Kobayashi, K., Marashi, H. \& Hoogenboom, G. Gene-based modeling for rice: An opportunity to enhance the simulation of rice growth and development?. J. Theor. Biol. 249, 593-605. https://doi.org/10.1016/j.jtbi.2007.08.022 (2007).

32. Soler, C. M. T., Sentelhas, P. C. \& Hoogenboom, G. Application of the CSM-CERES-Maize model for sowing date evaluation and yield forecasting for maize grown off-season in a subtropical environment. Eur. J. Agron. 18, 165-177. https://doi.org/10. 1016/j.eja.2007.03.002 (2007).

33. Andarzian, B. et al. WheatPot: A simple model for spring wheat yield potential using monthly weather data. Biosyst. Eng. 99, 487-495. https://doi.org/10.1016/j.biosystemseng.2007.12.008 (2008).

34. Andarzian, B., Hoogenboom, G., Bannayan, M., Shirali, M. \& Andarzian, B. Determining optimum sowing date of wheat using CSM-CERES-Wheat model. J. Saudi Soc. Agric. Sci. 14, 189-199. https://doi.org/10.1016/j.jssas.2014.04.004 (2015).

35. Palosuo, T. et al. Simulation of winter wheat yield and its variability in different climates of Europe: A comparison of eight crop growth models. Eur. J. Agron. 35, 103-114. https://doi.org/10.1016/j.eja.2011.05.001 (2011).

36. Rötter, R. P. et al. Simulation of spring barley yield in different climatic zones of Northern and Central Europe: A comparison of nine crop models. Field Crops Res. 133, 23-36. https://doi.org/10.1016/j.fcr.2012.03.016 (2012).

37. Ran, H. et al. Capability of a solar energy-driven crop model for simulating water consumption and yield of maize and its comparison with a water-driven crop model. Agric. For. Meteorol. 287, 107955. https://doi.org/10.1016/j.agrformet.2020.107955 (2020). 
38. Keating, B. A. et al. An overview of APSIM, a model designed for farming systems simulation. Eur. J. Agron. 18, 267-288. https:// doi.org/10.1016/S1161-0301(02)00108-9 (2003).

39. Probert, M. E. \& Dimes, J. P. Modelling release of nutrients from organic resources using APSIM. In Modelling nutrient management in tropical cropping systems Vol. 114 (eds Delve, R. J. \& Probert, M. E.) 25-31 (ACIAR Proceedings, 2004).

40. Mohanty, M. et al. Simulating soybean-wheat cropping system: APSIM model parameterization and validation. Agric. Ecosyst. Environ. 152, 68-78. https://doi.org/10.1016/j.agee.2012.02.013 (2012).

41. George, N., Thompson, S. E., Hollingsworth, J., Orloff, S. \& Kaffka, S. Measurement and simulation of water-use by canola and camelina under cool-season conditions in California. Agric. Water Manag. 196, 15-23. https://doi.org/10.1016/j.agwat.2017. 09.015 (2018).

42. Bahri, H., Annabi, M., M'Hamed, H. C. \& Frija, A. Assessing the long-term impact of conservation agriculture on wheat-based systems in Tunisia using APSIM simulations under a climate change context. Sci. Total Environ. 692, 1223-1233. https://doi. org/10.1016/j.scitotenv.2019.07.307 (2019).

43. Ahmed, M. et al. Novel multimodel ensemble approach to evaluate the sole effect of elevated $\mathrm{CO}_{2}$ on winter wheat productivity. Sci. Rep. 9, 7813. https://doi.org/10.1038/s41598-019-44251-x (2019).

44. Eyni-Nargeseh, H., Deihimfard, R., Rahimi-Moghaddam, R. \& Mokhtassi-Bidgoli, A. Analysis of growth functions that can increase irrigated wheat yield under climate change. Meteorol. Appl. 27, 1-10. https://doi.org/10.1002/met.1804 (2020).

45. Rahimi-Moghaddam, S., Eyni-Nargeseh, H., Kalantar Ahmadi, S. A. \& Azizi, K. Towards withholding irrigation regimes and resistant genotypes as strategies to increase canola production in drought-prone environments: A modeling approach. Agric. Water Manag. 243, 106487. https://doi.org/10.1016/j.agwat.2020.106487 (2021).

46. Berghuijs, H. N. C. et al. Calibrating and testing APSIM for wheat-faba bean pure cultures and intercrops across Europe. Field Crops Res. 264, 108088. https://doi.org/10.1016/j.fcr.2021.108088 (2021).

47. METLE. National Report. Ministry of Equipment, Transport, Logistics and Water (last access 15.06.21), (2019).

48. HCP. Voluntary national review of the implementation of the sustainable development goals. High Comm. Plng. p. 188 (2020).

49. Hammer, G. L. et al. Adapting APSIM to model the physiology and genetics of complex adaptive traits in field crops. J. Exp. Bot. 61, 2185-2202. https://doi.org/10.1093/jxb/erq095 (2010).

50. Holzworth, D. P. et al. APSIM - evolution towards a new generation of agricultural systems simulation. Environ. Model. Softw. 62,327-350. https://doi.org/10.1016/j.envsoft.2014.07.009 (2014).

51. Gaydon, D. S. et al. Evaluation of the APSIM model in cropping systems of Asia. Field Crops Res. 204, 52-75. https://doi.org/ 10.1016/j.fcr.2016.12.015 (2017).

52. Climate Kelpie website. http://www.climatekelpie.com.au/manage-climate/decision-support-tools-for-managing-climate (2010).

53. McCown, R. L., Hammer, G. L., Hargreaves, J. N. G., Holzworth, D. P. \& Freebairn, D. M. APSIM: A novel software system for model development, model testing and simulation in agricultural systems research. Agric. Syst. 50, 255-271. https://doi.org/10. 1016/0308-521X(94)00055-V (1996).

54. Cichota, R., Vogeler, I., Werner, A., Wigley, K. \& Paton, B. Performance of a fertiliser management algorithm to balance yield and nitrogen losses in dairy systems. Agric. Syst. 162, 56-65. https://doi.org/10.1016/j.agsy.2018.01.017 (2018).

55. Laurenson, S., Cichota, R., Reese, P. \& Breneger, S. Irrigation runoff from a rolling landscape with slowly permeable subsoils in New Zealand. Irrig. Sci. 36, 121-131. https://doi.org/10.1007/s00271-018-0570-3 (2018).

56. Rodriguez, D. et al. Predicting optimum crop designs using crop models and seasonal climate forecasts. Sci. Rep. 8, 2231. https:// doi.org/10.1038/s41598-018-20628-2 (2018).

57. Archontoulis, S. V., Miguez, F. E. \& Moore, K. J. A methodology and an optimization tool to calibrate phenology of short-day species included in the APSIM PLANT model: Application to soybean. Environ. Model. Softw. 62, 465e477. https://doi.org/10. 1016/j.envsoft.2014.04.009 (2014)

58. Brown, H., Huth, N. \& Holzworth, D. Crop model improvement in APSIM: Using wheat as a case study. Eur. J. Agron. 100, 141-150. https://doi.org/10.1016/j.eja.2018.02.002 (2018).

59. Yang, X. et al. Cropping system productivity and evapotranspiration in the semiarid Loess Plateau of China under future temperature and precipitation changes: An APSIM-based analysis of rotational vs. Continuous systems. Agric. Water Manag. 229, 105959. https://doi.org/10.1016/j.agwat.2019.105959 (2020).

60. Balboa, G. R. et al. A systems-level yield gap assessment of maize-soybean rotation under highand low-management inputs in the Western US Corn Belt using APSIM. Agric. Syst. 174, 125-154. https://doi.org/10.1016/j.agsy.2019.04.008 (2019).

61. Yang, X. et al. Modelling the effects of conservation tillage on crop water productivity, soil water dynamics and evapotranspiration of a maize-winter wheat-soybean rotation system on the Loess plateau of China using APSIM. Agric. Syst. 166, 111-123. https://doi.org/10.1016/j.agsy.2018.08.005 (2018).

62. Mohanty, M. et al. Soil carbon sequestration potential in a Vertisol in central India- results from a 43-year long-term experiment and APSIM modeling. Agric. Syst. 184, 102906. https://doi.org/10.1016/j.agsy.2020.102906 (2020).

63. Vogeler, I., Thomas, S. \& van der Weerden, T. Effect of irrigation management on pasture yield and nitrogen losses. Agric. Water Manag. 216, 60-69. https://doi.org/10.1016/j.agwat.2019.01.022 (2019).

64. Bosi, C. et al. APSIM-tropical pasture: A model for simulating perennial tropical grass growth and its parameterisation for palisade grass (Brachiaria brizantha). Agric. Syst. 184, 102917. https://doi.org/10.1016/j.agsy.2020.102917 (2020).

65. Smethurst, P. J., Valadares, R. V., Huth, N. I., Almeida, A. C. \& Júlio, C. L. N. Generalized model for plantation production of Eucalyptus grandisand hybrids forgenotype-site-management applications. For. Ecol. Manag. 469, 118164. https://doi.org/10. 1016/j.foreco.2020.118164 (2020).

66. Xiao, D. P., Liu, D. L., Wang, B., Feng, P. Y. \& Tang, J. Z. Climate change impact on yields and water use of wheat and maize in the north China plain under future climate change scenarios. Agric. Water Manag. 238, 1-15. https://doi.org/10.1016/j.agwat. $2020.106238(2020)$

67. Seyoum, S., Rachaputi, R., Chauhan, Y., Prasanna, B. \& Fekybelu, S. Application of the APSIM model to exploit G $\times \mathrm{E} \times \mathrm{M}$ interactions for maize improvement in Ethiopia. Field Crops Res. 217, 113-124. https://doi.org/10.1016/j.fcr.2017.12.012 (2018).

68. Basche, A. D. \& DeLonge, M. S. Comparing infiltration rates in soils managed with conventional and alternative farming methods: A meta-analysis. PLoS ONE 14, e0215702. https://doi.org/10.1371/journal.pone.0215702 (2019).

69. Holzworth, D. et al. The development of a farming systems model (APSIM): A disciplined approach. In Proceedings of the iEMSs Third Biennial Meeting, Burlington, VT, USA, 9-13 July 2006 (International Environmental Modelling and Software Society, Manno, Switzerland, 2006).

70. Gaydon, D. S. The APSIM model-an overview. In SAC Monograph: The SAARC-Australia Project Developing Capacity in Cropping Systems Modelling for South Asia (eds Dr. Donald S. Gaydon et al.) 15-31 (2014).

71. Pinheiro, J. C. \& Bates, D. M. Mixed Effects Models in S and S-Plus (Statistics and Computing) (Springer, New York, 2000).

72. El Halimi, R. Nonlinear Mixed-effects Models and Bootstrap resampling: Analysis of Non-normal Repeated Measures in Biostatistical Practice. Amazon Books. 320 (2009).

73. Vock, D. M., Davidian, M., Tsiatis, A. A. \& Muir, A. J. Mixed model analysis of censored longitudinal data with flexible randomeffects density. Biostat. 13, 61-73. https://doi.org/10.1093/biostatistics/kxr026 (2012).

74. Beroho, M. et al. Analysis and prediction of climate forecasts in Northern Morocco: Application of multilevel linear mixed effects models using R Software. Heliyon 6, e05094. https://doi.org/10.1016/j.heliyon.2020.e05094 (2020). 
75. Laird, N. M. \& Ware, J. H. Random-effects models for longitudinal data. Biometrics 38, 963-974. https://doi.org/10.2307/25298 76 (1982).

76. Littell, R. C., Henry, P. R. \& Ammerman, C. B. Statistical analysis of repeated measures data using SAS procedures. J. Anim. Sci. Biotechnol. 76, 1216-1231. https://doi.org/10.2527/1998.7641216x (1998).

77. Bouyoucos, G. J. Direction for making mechanical analysis of soils by the hydrometer method. Soil Sci. 42, 225-230. https:// doi.org/10.1097/00010694-193609000-00007 (1936).

78. Nash, J. E. \& Sutcliffe, J. V. River flow forecasting through conceptual models, part I: A discussion of principles. J. Hydrol. 10, 282-290. https://doi.org/10.1016/0022-1694(70)90255-6 (1970).

79. Willmott, C. J., Robeson, S. M. \& Matsuura, K. A refined index of model performance. Int. J. Climatol. 32, 2088-2094. https:// doi.org/10.1002/joc.2419 (2011).

80. Loague, K. \& Green, R. E. Statistical and graphical methods for evaluating solute transport models; overview and application. J. Contam. Hydrol. 7, 51-73. https://doi.org/10.1016/0169-7722(91)90038-3 (1991).

81. Willmott, C. J. et al. Statistic for the evaluation and comparison of models. J. Geophys. Res. 90, 8995-9005. https://doi.org/10. 1029/JC090iC05p08995 (1985).

82. Jones, C. A., Kiniry, J. R. \& Dyke, P. T. CERES-Maize, A simulation model of maize growth and development 1 st edn. (Texas University Press, College Station, 1986).

83. Dardanelli, J. L., Bacheier, O. A., Sereno, R. \& Gil, R. Rooting depth and soil water extraction patterns of different crops in a silty loam Haplustoll. Field Crops Res. 54, 29-38. https://doi.org/10.1016/S0378-4290(97)00017-8 (1997).

84. Probert, M. E., Dimes, J. P., Keating, B. A., Dalal, R. C. \& Strong, W. M. APSIM’s water and nitrogen modules and simulation of the dynamics of water and nitrogen in fallow systems. Agric. Syst. 56, 1-28. https://doi.org/10.1016/S0308-521X(97)00028-0 (1998).

85. Littleboy, M., Freebairn, D. M., Silburn, D. M., Woodruff, D. R., Hammer, G. L. PERFECT version 3. A computer simulation model of productivity erosion runoff functions to evaluate conservation techniques. Queensland department of natural resources and department of plant industries. Queensland Dep. Prim. Ind., Queensland, Australia (1999).

86. Dalgliesh, N. P. \& Foale, M. A. Soil matters: Monitoring soil water and nutrients in dryland farming. Agric. Prod. Sys. Res. Unit, Toowoomba, Australia; http://hdl.handle.net/102.100.100/217161?index=1 (1998).

87. Malone, R. W. et al. Evaluating and predicting agricultural management effects under tile drainage using modified APSIM. Geoderma 140, 310-322. https://doi.org/10.1016/j.geoderma.2007.04.014 (2007).

88. Cresswell, H. P. et al. Catchment response to farm scale land use change. CSIRO and NSW Dept. of Ind. \& Invest. (2009).

89. Hammer, G. L. et al. Can changes in canopy and/or root system architecture explain historical maize yield trends in the U.S. Corn Belt?. Crop Sci. 49, 299-312. https://doi.org/10.2135/cropsci2008.03.0152 (2009).

90. Archontoulis, S. V., Miguez, F. E. \& Moore, K. J. Evaluating APSIM maize, soil water, soil nitrogen, manure, and soil temperature modules in the Midwestern United States. Agron. J. 106, 1025. https://doi.org/10.2134/agronj2013.0421 (2014).

91. MacCarthy, D. S., Sommer, R. \& Vlek, P. L. G. Modeling the impacts of contrasting nutrient and residue management practices on grain yield of sorghum (Sorghum bicolor (L.) Moench) in a semi-arid region of Ghana using APSIM. Field Crops Res. 113, 105-115. https://doi.org/10.1016/j.fcr.2009.04.006 (2009).

92. Yang, Y. et al. Water use efficiency and crop water balance of rainfed wheat in a semi-arid environment: Sensitivity of future changes to projected climate changes and soil type. Theor. Appl. Climatol. 123, 565-579. https://doi.org/10.1007/s00704-0151376-3 (2016).

93. Deihimfard, R., Eyni-Nargeseh, H. \& Mokhtassi-Bidgoli, A. Effect of future climate change on wheat yield and water use efficiency under semi-arid conditions as predicted by APSIM-wheat model. Int. J. Plant Prod. 12, 115-125. https://doi.org/10.1007/ s42106-018-0012-4 (2018).

94. Zhao, P. et al. The adaptability of Apsim-wheat model in the middle and lower reaches of the Vangtze river plain of china: A case study of winter wheat in hubei province. Agronomy 10, 981. https://doi.org/10.3390/agronomy10070981 (2020).

95. SHNP, D. S., Takahashi, T., Okada, K. Evaluation of APSIM-wheat to simulate the response of yield and grain protein content to nitrogen application on an Andosol in Japan. Plant Prod. Sci. https://doi.org/10.1080/1343943X.2021.1883989 (2021).

96. O'Leary, G. J. et al. Response of wheat growth, grain yield and water use to elevated $\mathrm{CO} 2$ under afree-air $\mathrm{CO} 2$ Enrichment (FACE) experiment and modelling in a semi-arid environment. Glob. Change Biol. 21, 2670-2686. https://doi.org/10.1111/gcb. 12830 (2015).

97. Lilley, J. M. \& Kirkegaard, J. A. Farming system context drives the value of deep wheat roots in semi-arid environments. J. Exp. Bot. 67, 3665-3681. https://doi.org/10.1093/jxb/erw093 (2016).

98. Whitbread, A. M., Hoffmann, M. P., Davoren, C. W., Mowat, D. \& Baldock, J. A. Measuring and modeling the water balance in low-Rainfall cropping systems. Trans. ASABE 60, 2097-2110. https://doi.org/10.13031/trans.12581 (2017).

99. Silungwe, F. R. et al. Crop upgrading strategies and modelling for rainfed cereals in a semi-arid climate-a review. Water 10, 356. https://doi.org/10.3390/w10040356 (2018).

100. Hussain, J., Khaliq, T., Ahmad, A. \& Akhtar, J. Performance of four crop model for simulations of wheat phenology, leaf growth, biomass and yield across planting dates. PLoS ONE 13, e0197546. https://doi.org/10.1371/journal.pone.0197546 (2018).

101. Asseng, S., Turner, N. C. \& Keating, B. A. Analysis of water- and nitrogen-use efficiency of wheat in a Mediterranean climate. Plant Soil 233, 127-143. https://doi.org/10.1023/A:1010381602223 (2001).

102. Moeller, C., Pala, M., Manschadi, A. M., Meinke, H. \& Sauerborn, J. Assessing the sustainability of wheat-based cropping systems using APSIM: Model parameterisation and evaluation. Aust. J. Agric. Res. 58, 75-86. https://doi.org/10.1007/s11625-013-0228-2 (2007).

103. Bassu, S., Asseng, S., Giunta, F. \& Motzo, R. Optimizing triticale sowing densities across the Mediterranean Basin. Field Crops Res. 144, 167-178. https://doi.org/10.1016/j.fcr.2013.01.014 (2013).

104. Bationo, A., Mokwunye, U., Vlek, P. L. G., Koala, S. \& Shapiro, B. I. Soil fertility management for sustainable land use in the West African Sudano-Sahelian Zone. In Soil Fertility Management in Africa: A Regional Perspective, African Academy of Sciences Centro Internacional de Agricultura Tropical (CIAT); Tropical Soil Biology and Fertility (TSBF) (eds Gichuri, M. P. et al.) 253-292 (Academic and Scientific Publishing, Nairobi, 2003).

105. Bernstein, L. et al. IPCC, 2007: Climate Change 2007: Synth. Rep. Geneva: IPCC. ISBN 2-9169-122-4 (2008).

106. Tramblay, Y. et al. Climate change impacts on extreme precipitation in Morocco. Glob. Planet Change 82, 104-114. https://doi. org/10.1016/j.gloplacha.2011.12.002 (2012).

107. Tramblay, Y., Ruelland, D., Somot, S., Bouaicha, R. \& Servat, E. High-resolution Med-CORDEX regional climate model simulations for hydrological impact studies: A first evaluation of the ALADIN-Climate model in Morocco. Hydrol. Earth Syst. Sci. 17, 3721-3739. https://doi.org/10.5194/hess-17-3721-2013 (2013).

108. Seif-Ennasr, M. et al. Climate change and adaptive water management measures in Chtouka Ait Baha region (Morocco). Sci. Total Environ. 573, 862-875. https://doi.org/10.1016/j.scitotenv.2016.08.170 (2016).

109. Hirich, A., Fatnassi, H., Ragab, R. \& Choukr-Allah, R. Prediction of climate change impact on corn grown in the South of Morocco using the saltmed model. J. Irrigat. Drain. Eng. 65, 9-18. https://doi.org/10.1002/ird.2002 (2016).

110. Ouhamdouch, S. \& Bahir, M. Climate change impact on future rainfall and temperature in semi-arid areas (Essaouira basin, Morocco). Environ. Process. 4, 975-990. https://doi.org/10.1007/s40710-017-0265-4 (2017). 
111. Brouziyne, Y. et al. Modelling sustainable adaptation strategies toward a climate-smart agriculture in a Mediterranean watershed under projected climate change scenarios. Agric. Syst. 162, 154-163. https://doi.org/10.1016/j.agsy.2018.01.024 (2018).

112. Dosio, A. \& Panitz, H.-J. Climate change projections for CORDEX-Africa with COSMO-CLM regional climate model and differences with the driving global climate models. Clim. Dyn. 46, 1599-1625. https://doi.org/10.1007/s00382-015-2664-4 (2016).

113. Zeroual, A., Assani, A. A., Meddi, M. \& Alkama, R. Assessment of climate change in Algeria from 1951 to 2098 using the Köppen-Geiger climate classification scheme. Clim. Dyn. 52, 227-243. https://doi.org/10.1007/s00382-018-4128-0 (2018).

114. Mami, A. et al. Future climatic and hydrologic changes estimated by bias-adjusted regional climate model outputs of the CordexAfrica project: Case of the Tafna basin (North-Western Africa). Int. J. Glob. Warm. 23, 58-90. https://doi.org/10.1504/IJGW. 2021.112489 (2021).

115. Arora, V. K. \& Gajri, P. R. Evaluation of a crop growth-water balance model for analyzing wheat responses to climate and waterlimited environments. Field Crops Res. 59, 213-224. https://doi.org/10.1016/S0378-4290(98)00124-5 (1998).

116. Aggarwal, P. K., Talukdar, K. K., Mall, R. K. Potential yields of rice-wheat system in the Indo-Gangetic plains of India. RiceWheat Consortium Paper Series 10. New Delhi, India. RWCIGP, CIMMYT. p. 16 (2000).

117. Arora, V. K., Singh, H. \& Singh, B. Analyzing wheat productivity responses to climatic, irrigation and fertilizer-nitrogen regimes in a semi-arid sub-tropical environment using the CERES-Wheat model. Agric. Water Manag. 94, 22-30. https://doi.org/10. 1016/j.agwat.2007.07.002 (2007).

118. Timsina, J. et al. Evaluation of options for increasing yield and water productivity of wheat in Punjab, India using the DSSATCSM-CERES-wheat model. Agric. Water Manag. 95, 1099-1110. https://doi.org/10.1016/j.agwat.2008.04.009 (2008).

119. Balwinder-Singha, Humphreys \& E., Gaydon, D. S., Eberbach, P. L.,. Evaluation of the effects of mulch on optimum sowing date and irrigation management of zero till wheat in central Punjab, India using APSIM. Field Crops Res. 197, 83-96. https://doi.org/ 10.1016/j.fcr.2016.08.016 (2016)

120. Choudhury, A. K. et al. Optimum Sowing Window and Yield Forecasting for Maize in Northern and Western Bangladesh Using CERES Maize Model. Agronomy 11, 635. https://doi.org/10.3390/agronomy11040635 (2021).

121. Sun, H., Shao, I., Chen, S. \& Zhang, X. Effects of sowing time and rate on crop growth and radiation use efficiency of winter wheat in the North China Plain. Int. J. Plant Prod. 7, 117-138 (2013).

122. $\mathrm{Qu}, \mathrm{H}$. J. et al. Effects of plant density and seeding date on accumulation and translocation of dry matter and nitrogen in winter wheat cultivar Lankao Aizao 8. Acta Agron. Sin. 35, 124-131. https://doi.org/10.3724/SP.J.1006.2009.00124 (2009).

123. Liu, P. et al. Effect of seeding rate and sowing date on population traits and grain yield of drip irrigated winter wheat. J. Triticeae Crops 33, 1202-1207 (2013).

124. Lu, H. D., Xue, J. Q., Hao, Y. C., Zhang, R. H. \& Gao, J. Effects of sowing time on spring maize (Zea mays L.) growth and water use efficiency in rainfed dryland. Acta Agron. Sin. 41, 1906-1914 (2015).

125. Taylor, S. \& Evans, C. Wheat: Susceptibility of varieties to common root rot. CWFS Research Compendium (2005).

126. Bowden, P. et al. Wheat growth \& development. NSW Department of Primary Industries, State of New South Wales, p. 104 (2008).

127. DEEDI. Wheat varieties. Queensland Department of Employment, Economic Development and Innovation (DEEDI). p. 20 (2010).

128. Lush, D. et al. Queensland wheat varieties. Grains Research and Development Corporation (GRDC) and the Queensland Department of Agriculture, Fisheries and Forestry (DAFF). p. 20 (2015).

129. Greenwood, J. R. Wheat inflorescence architecture. Thesis report, Australian National University, p. 218 (2017).

130. Lush, D., Forknall, C., Neate, S., Sheedy, J. Queensland wheat varieties. Grains Research and Development Corporation (GRDC) and the Queensland Department of Agriculture and Fisheries (DAF). p. 20 (2018).

131. Hines, S., Andrews, M., Scott, W. R. \& Jack, D. Sowing depth and nitrogen effects on emergence of a range of New Zealand wheat cultivars. Proc. Agron. Soc. N. Z. 21, 67-72 (1991).

132. Zaicou, C. et al. Wheat variety guide 2008 Western Australia. Department of Agriculture and Food, Western Australia, Perth. Bull. 4733 (2008).

133. Kelbert, A. J., Spaner, D., Briggs, K. G. \& King, J. R. The association of culm anatomy with lodging susceptibility in modern spring wheat genotypes. Euphytica 136, 211-221. https://doi.org/10.1023/B:EUPH.0000030670.36730.a4 (2004).

134. Mason, H., Navabi, A., Frick, B., O'Donovan, J. \& Spaner, D. Cultivar and seeding rate effects on the competitive ability of spring cereals grown under organic production in northern Canada. Agron. J. 99, 1199-1207. https://doi.org/10.2134/agronj2006.0262 (2007).

135. Shah, L. et al. Improving lodging resistance: Using wheat and rice as classical examples. Int. J. Mol. Sci. 20, 4211. https://doi.org/ 10.3390/ijms20174211 (2019).

136. Mitter, V. et al. A high-throughput greenhouse bioassay to detect crown rot resistance in wheat germplasm. Plant Pathol. 55, 433-441. https://doi.org/10.1111/j.1365-3059.2006.01384.x (2006).

137. Hare, R. Agronomy of the durum wheats Kamilaroi, Yallaroi, Wollaroi and EGA Bellaroi. NSW Department of Primary Industries, State of New South Wales, Primefact 140 (2006).

138. DPI\&F. Wheat varieties for Queensland. Department of Primary Industries and Fisheries (DPI\& $F)$, State of Queensland, p. 12 (2007).

139. Singh, B. et al. Inheritance and chromosome location of leaf rust resistance in durum wheat cultivar Wollaroi. Euphytica 175, 351-355. https://doi.org/10.1007/s10681-010-0179-y (2010).

140. Bansal, U. K., Kazi, A. G., Singh, B., Hare, R. A. \& Bariana, H. S. Mapping of durable stripe rust resistance in a durum wheat cultivar Wollaroi. Mol Breed 33, 51-59. https://doi.org/10.1007/s11032-013-9933-x (2014).

\section{Acknowledgements}

The authors would like to thank farmers of the Rhamna region for their assistance during the field survey. Besides, we are indebted to acknowledge the Regional Office for Agricultural Development of Haouz (ORMVAH), the Regional Directorate of Agriculture of Marrakech-Safi (DRA) and the National Office of the Agricultural Council of Benguerir (ONCA) for providing us with climatic and agronomic data.

\section{Author contributions}

H.B.: Conceived and designed the experiments; Performed the experiments; Analyzed and interpreted the data; Contributed reagents, materials, analysis tools or data; Wrote the paper. F.K.: Conceived and designed the experiments; Contributed reagents, materials, analysis tools or data; Supervised the research and reviewed the manuscript.

\section{Funding}

This research was funded by AgriEdge of OCP foundation in the framework of the Digital Farming Project between the Mohammed VI Polytechnic University, Morocco (UM6P) and Massachusetts Institute of Technology, USA (MIT). 


\section{Competing interests}

The authors declare no competing interests.

\section{Additional information}

Correspondence and requests for materials should be addressed to H.B.

Reprints and permissions information is available at www.nature.com/reprints.

Publisher's note Springer Nature remains neutral with regard to jurisdictional claims in published maps and institutional affiliations.

(c) (i) Open Access This article is licensed under a Creative Commons Attribution 4.0 International License, which permits use, sharing, adaptation, distribution and reproduction in any medium or format, as long as you give appropriate credit to the original author(s) and the source, provide a link to the Creative Commons licence, and indicate if changes were made. The images or other third party material in this article are included in the article's Creative Commons licence, unless indicated otherwise in a credit line to the material. If material is not included in the article's Creative Commons licence and your intended use is not permitted by statutory regulation or exceeds the permitted use, you will need to obtain permission directly from the copyright holder. To view a copy of this licence, visit http://creativecommons.org/licenses/by/4.0/.

(C) The Author(s) 2021 